\title{
Systematic Review \\ SARS-CoV-2 Vaccines during Pregnancy and Breastfeeding: A Systematic Review of Maternal and Neonatal Outcomes
}

\author{
Domenico Umberto De Rose, Guglielmo Salvatori $\mathbb{D}^{\mathbb{C}}$, Andrea Dotta $\mathbb{C}^{\circledR}$ and Cinzia Auriti * \\ Neonatal Intensive Care Unit, Medical and Surgical Department of Fetus-Newborn-Infant, "Bambino Gesù" \\ Children's Hospital IRCCS, 00165 Rome, Italy; domenico.derose@opbg.net (D.U.D.R.); \\ guglielmo.salvatori@opbg.net (G.S.); andrea.dotta@opbg.net (A.D.) \\ * Correspondence: cinzia.auriti@opbg.net; Tel.: +39-06-6859-2427; Fax: +39-06-6859-3916
}

\begin{abstract}
Objective: This systematic review summarizes current knowledges about maternal and neonatal outcomes following COVID-19 vaccination during pregnancy and breastfeeding. (2) Study design: PubMed, Cochrane Library, and the Education Resources Information Center (ERIC) were searched up to 27 October 2021. The primary outcome was to estimate how many pregnant and lactating women were reported to be vaccinated and had available maternal and neonatal outcomes. (3) Results: Forty-five studies sourcing data of 74,908 pregnant women and 5098 lactating women who received COVID-19 vaccination were considered as eligible. No major side-effects were reported, especially during the second and third trimester of pregnancy and during breastfeeding. Conversely, available studies revealed that infants received specific SARS-CoV-2 antibodies after maternal vaccination. (4) Conclusions: Vaccination against the SARS-CoV-2 virus should be recommended for pregnant women, after the pros and cons have been adequately explained. In particular, given the still limited evidence and considering that fever during the first months of gestation increases the possibility of congenital anomalies, they should be carefully counseled. The same considerations apply to breastfeeding women, also considering the immune responses that mRNA vaccines can generate in their human milk.
\end{abstract}

Citation: De Rose, D.U.; Salvatori, G.; Dotta, A.; Auriti, C. SARS-CoV-2 Vaccines during Pregnancy and Breastfeeding: A Systematic Review of Maternal and Neonatal Outcomes. Viruses 2022, 14, 539. https:/ / doi.org/10.3390/v14030539

Academic Editor: Hin Chu

Received: 13 January 2022

Accepted: 3 March 2022

Published: 5 March 2022

Publisher's Note: MDPI stays neutral with regard to jurisdictional claims in published maps and institutional affiliations.

Keywords: neonates; COVID-19; infants; mothers; pregnancy; fetuses; miscarriage; malformations; women

\section{Introduction}

Physiological, mechanical, and immunologic changes in pregnant women could influence their possibility of being attacked by the severe acute respiratory syndrome coronavirus 2 (SARS-CoV-2) [1]. Main symptoms of the disease (COVID-19) are related to an impaired microcirculatory function; indeed, infected pregnant women are at increased risk of preeclampsia (PE)-like symptoms [2] and of need for hospitalization and intensive care unit admission [3]. Given that the incidence of obstetrical complications, such as preterm birth, appears to be proportional to the severity of the infection, infants born to infected mothers with a more severe clinical course may have a worse outcome, mainly due to neonatal morbidity and mortality associated with prematurity. Therefore, the immunization of pregnant women against SARS-CoV-2 appears to be justified [4].

Although no conclusive evidence is yet completely available regarding the effectiveness and safety of COVID-19 vaccines in pregnancy, due to the non-inclusion of these women in clinical trials evaluating vaccines, the studies performed to date have allowed detecting a significant lower risk of contracting SARS-CoV-2 infection among vaccinated than unvaccinated pregnant women. The number of pregnant women vaccinated against COVID-19 to date, globally, has exceeded hundreds of thousands with no adverse event reports in excess of the nonpregnant population [5]. The same goes for the efficacy of vaccination during breastfeeding, which is considered to be similar to that among nonpregnant women. Currently there is unanimous consensus that there is no biological plausibility 
in support of a possible harm to infants nursed by vaccinated mothers [6]. Regarding the fertility of women who undergo vaccination against COVID-19, public health agencies and scientific societies internationally ruled out a possible association between vaccine and fertility problems [7].

Our aim was to summarize the evidence in the literature on the outcomes of vaccination against SARS-CoV-2 in pregnant women and in women who have recently delivered, as well as the possible effects of vaccines currently used (Figure 1) on their newborns.

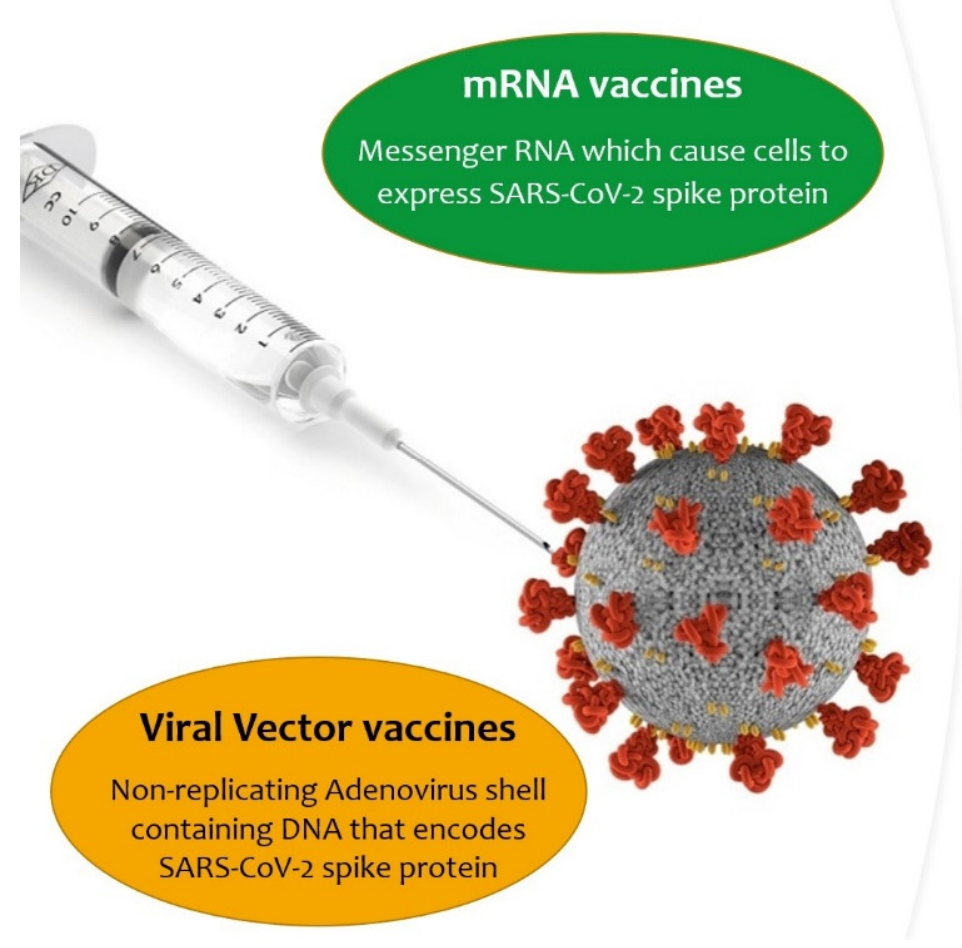

\section{Available COVID-19 vaccines}

\section{mRNA vaccines}

- Pfizer-BioNTech BNT162b2 (Cominarty $\left.{ }^{\circledR}\right)$

- Moderna mRNA-1273 $\left(\right.$ Spikevax $^{\circledR}$ )

\section{Viral Vector vaccines}

- Oxford-Astra Zeneca ChAdOx1 $\left(\right.$ Vaxzevria $\left.^{\circledR}\right)$

- Johnson \& Johnson's (Janssen ${ }^{\circledR}$ )

Figure 1. Available COVID-19 vaccines authorized for use by European Medicines Agency (EMA) at the moment of the literature search.

\section{Materials and Methods}

\subsection{Search Strategy and Study Selection}

This systematic review was performed following PRISMA guidelines [8]. Search terms included "SARS-CoV-2" OR "COVID-19" AND "vaccination" OR "vaccine" AND "pregnancy" OR "pregnant" OR "breastfeeding". We considered studies providing information about maternal and/or child outcomes after maternal SARS-CoV-2 vaccination with a mRNA-based vaccine published after 1 January 2021. We did not apply limitations on study design to include all available literature, but preprint studies were not considered. The selection of studies was made through PubMed (http:/ / www.ncbi.nlm.nih.gov/pubmed/, accessed on 27 October 2021), the Cochrane Library (https:/ / www.cochranelibrary.com/ advanced-search, accessed on 27 October 2021), and the Education Resources Information Center (ERIC, https: / / eric.ed.gov/, accessed on 27 October 2021) (Box 1).

The search was conducted as follows: Dr. De Rose (D.U.D.R.) identified relevant studies by reading the abstract and searching for additional studies through the reference lists of the selected papers. Then, Dr. De Rose (D.U.D.R.) and Dr. Auriti (C.A.) independently reviewed the studies by checking titles and abstracts of the articles and by deciding whether to include each article or not. 
Box 1. Different COVID-19 vaccine types to date.

Different types of vaccines are under research to develop an effective vaccine against COVID-19:

- $\quad$ mRNA vaccines: based on messenger RNA (mRNA) or a self-replicating RNA that provides the genetic information required to produce the spike protein: Pfizer-BioNTech BNT162b2 $\left(\right.$ Comirnaty ${ }^{\circledR}$ ) and Moderna mRNA-1273 (Spikevax ${ }^{\circledR}$ );

- Viral-vector vaccines: an existing virus that is incompetent for replication but contains DNA that encodes for the spike protein. In the case of ChAdOx-1S, developed by the University of Oxford and AstraZeneca (Vaxzevria ${ }^{\circledR}$ ), the vector is a modified chimpanzee adenovirus; in the case of Johnson \& Johnson's Ad26.COV2.S (Janssen ${ }^{\circledR}$ ), the vector is a recombinant human adenovirus (Ad 26-serotype 26); in the case of the Russian Gam-COVID-Vac (Sputnik V ${ }^{\circledR}$ ), two recombinant replication-defective human adenoviruses were used (Ad26 and Ad5-serotype 5); in the case of Ad5-nCov (Convidecia $\left.{ }^{\circledR}\right)$, the vector is similarly the human adenovirus serotype 5 (Ad5);

- Recombinant protein vaccines: based on the laboratory synthesis of the spike protein, the receptor-binding domain (RBD), or virus-like particles. This category includes the American Nuvaxovid ${ }^{\circledR} /$ Indian Covovax ${ }^{\circledR}$, the Russian EpiVacCorona ${ }^{\circledR}$, the Chinese ZF2001 (Zifivax ${ }^{\circledR}$ ), the Cuban Soberana- ${ }^{\circledR}$, and the Sanofi-GSK VAT00008;

- Inactivated viral vaccines: the SARS-CoV-2 virus has been cultivated in cell cultures and chemically inactivated. This category includes the Chinese CoronaVac ${ }^{\circledR}$ and the Indian Covaxin ${ }^{\circledR}$;

- Live-attenuated virus vaccines: a genetically weakened variant of the virus that replicates to a limited amount but does not cause illness while eliciting an immune response, as for measles, mumps, and rubella (MMR) vaccine;

- DNA vaccines: modified plasmids that carry genes that typically code for the spike protein, which is then produced in the vaccinated individual, as in Indian ZyCoV-D ${ }^{\circledR}$ COVID vaccine.

How do current available vaccines work?

The Pfizer-BioNTech BNT162b2 vaccine and Moderna mRNA-1273 vaccine contain mRNA encoding for spike membrane proteins, encapsulated in lipid nanoparticles. Oxford-AstraZeneca ChAdOx1 contains SARS-CoV-2 virus cDNA fragments encapsulated in a viral vector. Both are non-replicants and self-destroying. When administered, macrophages and dendritic cells grab particles and convert them into proteins which are degraded into peptides and then exposed as antigens. Antigenic viral peptides are presented to major histocompatibility complexes (MHC) I and II and identified by helper T lymphocytes, causing B cells to synthesize neutralizing antibodies and cytotoxic $\mathrm{T}$ lymphocytes that kill infected cells.

Neutralizing antibodies directed to the virus membrane glycoproteins such as the spike protein and nucleocapsid proteins drive the humoral immune response to the SARS-CoV-2 virus. These antibodies prevent the virus from entering cells and, hence, its infectious capacity. However, not all antibodies have neutralizing activity, and some can increase the activity of the virus. Therefore, to solve this problem, mRNA fractions were isolated and encapsulated within lipid nanoparticles to create mRNA vaccines. COVID-19 infection is the first infection to be prevented with mRNA vaccines, and the vaccine underwent many tests quickly before being administered to humans. Both viral-vector vectors and mRNA vaccines induce a cell-mediated response by cytotoxic Th1 and $\mathrm{CD}^{+}$lymphocytes that recognize and digest viral antigens exposed by $\mathrm{MCH}$ class I molecules. As of yet, the induction of regulatory $\mathrm{T}$ cells in the vaccine-induced immune response has not been reported. Other COVID-19 vaccine types are now being studied in phase 1, 2, and 3 clinical trials (https:// covid19.trackvaccines.org/vaccines/).

\subsection{Assessment of Risk of Bias}

We evaluated the quality of included cohort studies and the risk of bias using the Newcastle-Ottawa Scale (NOS). The NOS comprises "participant selection", "comparability of study groups," and "assessment of outcome or exposure". A score above 6-7 denotes a reasonable quality.

\section{Results}

\subsection{Study Selection Process}

The searches identified 1345 potentially relevant papers and studies, while 576 after duplicates were removed. After title and abstract screening, 60 full-text studies were considered potentially eligible for inclusion. A flowchart of study selection process is reported in Figure 2. We considered 46 records: 30 of them included pregnant mothers [9-38], two 
studies included both pregnant and lactating mothers [39,40], and 14 studies included lactating mothers [41-54]. Most studies were conducted in the United States (41.3\%) and Israel $(26.1 \%)$, along with three in Italy (6.5\%), two in Spain (4.3\%) and in Poland (4.3\%), and the remaining (17.2\%) in the United Kingdom, Qatar, Belgium, Germany, Norway, Portugal, the Netherlands, and Singapore.

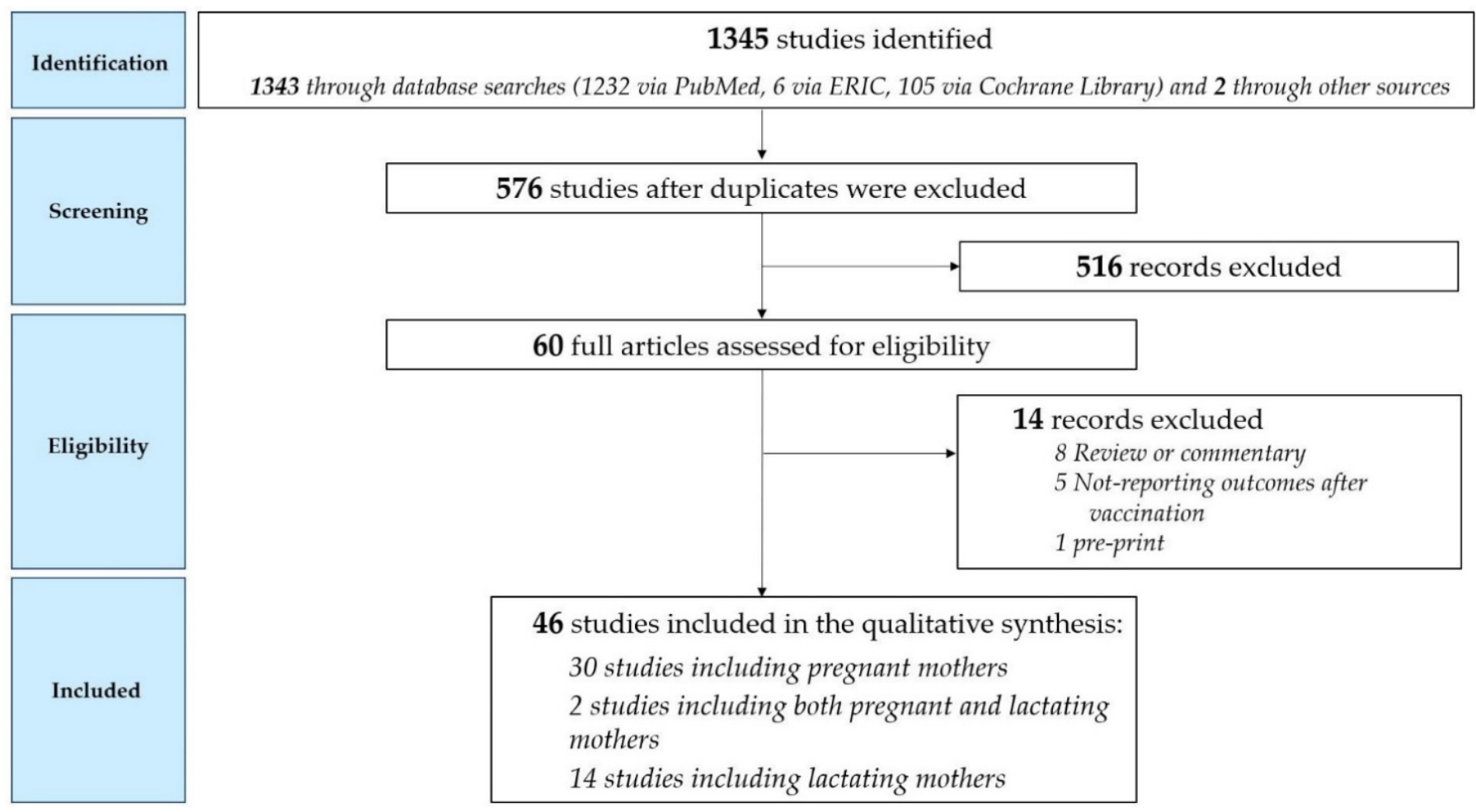

Figure 2. Study selection process.

Most cohort studies including pregnant women had a reasonable quality, as reported in Figure 3 (case series and case reports without a nonexposed group could not be considered).

Most studies including breastfeeding mothers reported only data about exposed women, without a control group; the remaining six studies had a reasonable quality, as reported in Figure 4.

\subsection{Synthesis of Results in Pregnant Women}

The characteristics and most relevant findings of the included studies about vaccination during pregnancy are reported in Table 1. The most relevant question concerns the safety of vaccination administered during pregnancy. No major adverse effects during pregnancy were reported.

To date, the largest study on the safety profile of mRNA vaccines during pregnancy is a cross-sectional survey published by Shimabukuro et al. in the New England Journal of Medicine, who reported preliminary findings from three US vaccine safety monitoring systems [34]. From 14 March 2020 to 28 February 2021 the authors surveyed over 35,000 women aged 16 to 54, identified as pregnant from their inclusion in various pregnancy registries. Among those women, 4000 provided information on the outcome; 827 of these delivered, and 29,000 reported post-vaccination symptoms. The limitation of the study is that all pregnant women were vaccinated in the third trimester, and this ruled out the possibility of evaluating some of the possible adverse effects of vaccinations on the progress of pregnancy and on newborns. However, although not fully comparable, the estimate of obstetrical and neonatal complications of maternal vaccination $(n=827)$ is similar to that described in studies on pregnant women conducted in the pre-COVID-19 period [30]. 
Beharier et al. 2021

Blakeway et al. 2021

Bleicher et al., 2021

Bookstein Peretz et al., 2021

Butt et al., 2021

Collier et al., 2021

Dagan et al., 2021

Goldshtein et al., 2021

Gray et al., 2021

Kadali et al., 2021

Kashani-Ligumsky et al., 2021

Kharbanda et al., 2021

Magnus et al., 2021

Morgan et al., 2021

Nir et al., 2021

Prabhu et al., 2021

Rottenstreich et al., 2021

Shanes et al., 2021

Shimabukuro et al., 2021

Wainstock et al., 2021

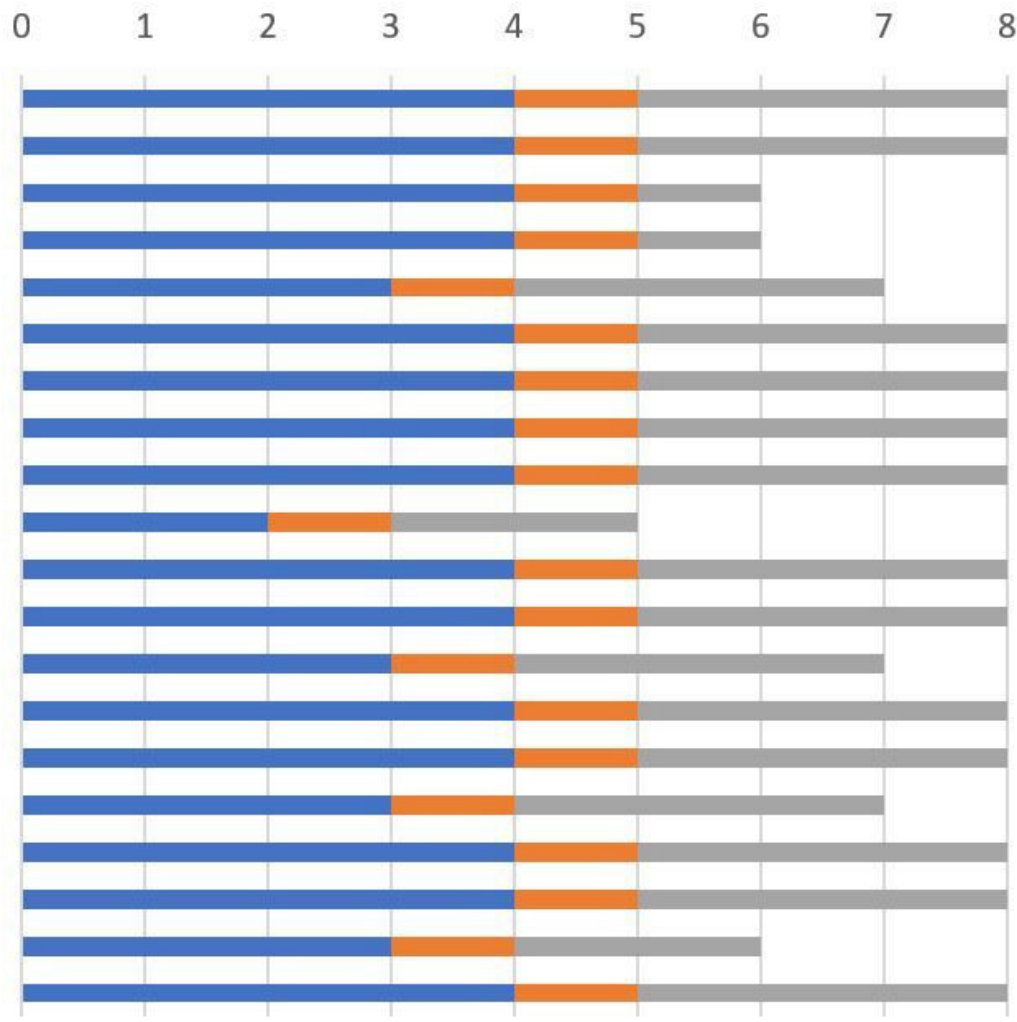

- Selection Comparability = Outcome

Figure 3. Quality assessment of included cohort studies involving pregnant women through "Newcastle-Ottawa Scale for cohort studies".

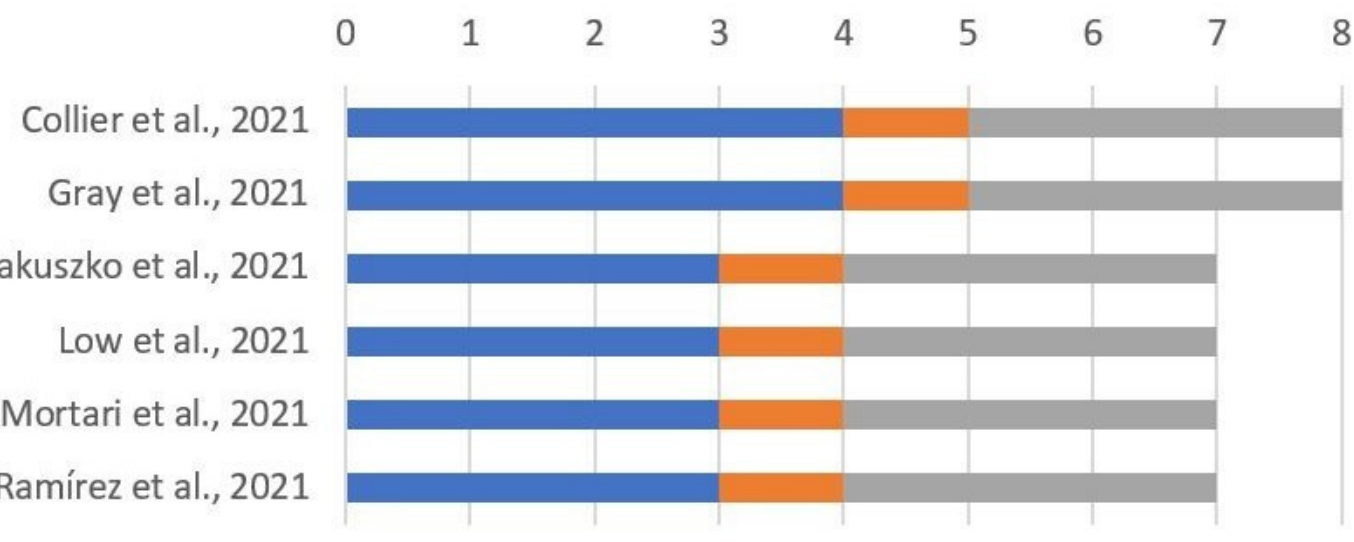

Selection Comparability Outcome

Figure 4. Quality assessment of included cohort studies involving breastfeeding mothers through "Newcastle-Ottawa Scale for cohort studies". 
Table 1. List of the 32 studies including pregnant mothers who received SARS-CoV-2 vaccination.

\begin{tabular}{|c|c|c|c|c|c|c|}
\hline $\begin{array}{l}\text { First Author, } \\
\text { Year }\end{array}$ & $\begin{array}{l}\text { Country, } \\
\text { Design }\end{array}$ & $\begin{array}{l}\text { Type of Vaccine } \\
\text { (Doses Given) }\end{array}$ & $\begin{array}{c}\text { Vaccinated } \\
\text { Pregnant } \\
\text { Women }(n)\end{array}$ & $\begin{array}{c}\text { First } \\
\text { Vaccine Dose } \\
\text { GA }^{*}\end{array}$ & Outcome & Conclusions \\
\hline $\begin{array}{c}\text { Beharier, } 2021 \\
\text { [9] }\end{array}$ & $\begin{array}{l}\text { Israel, } \\
\text { prospective, } \\
\text { multicenter }\end{array}$ & $\begin{array}{c}\text { Pfizer-BioNTech } \\
\text { BNT162b2 (2 } \\
\text { doses) }\end{array}$ & 86 & $\begin{array}{l}\text { Mean } \pm \text { SD: } \\
34.5 \pm 7.5\end{array}$ & $\begin{array}{l}\text { Antibodies in } \\
\text { maternal blood } \\
\text { and in umbilical } \\
\text { cord blood }\end{array}$ & $\begin{array}{l}\text { Strong maternal humoral } \\
\text { IgG } \\
\text { response (anti-S and RBD) } \\
\text { that crosses the placenta } \\
\text { barrier and approaches } \\
\text { maternal titers in the fetus } \\
\text { within } 15 \text { days following the } \\
\text { first dose. }\end{array}$ \\
\hline
\end{tabular}

Lower uptake among younger women, non-White ethnicity, and lower socioeconomic background. In a propensity score-matched cohort, the rates of adverse pregnancy outcomes were similar to that of unvaccinated pregnant women: stillbirth, fetal abnormalities, postpartum hemorrhage, cesarean delivery, small for gestational age, maternal high-dependency unit or ICU admission, or NICU admission.

\begin{tabular}{|c|c|c|c|c|c|}
\hline $\begin{array}{c}\text { Bleicher, } 2021 \\
\text { [11] }\end{array}$ & $\begin{array}{c}\text { Israel, } \\
\text { an interim } \\
\text { analysis of a } \\
\text { prospective study }\end{array}$ & $\begin{array}{c}\text { Pfizer-BioNTech } \\
\text { BNT162b2 } \\
\text { (at least one dose) }\end{array}$ & 80 & $\begin{array}{c}1 \text { st } \\
\text { trimester } \\
(17.8 \%), 2 \text { nd } \\
\text { trimester } \\
(54.5 \%), 3 \mathrm{rd} \\
\text { trimester } \\
(27.7 \%)\end{array}$ & $\begin{array}{l}\text { Complications in } \\
\text { vaccinated and } \\
\text { nonvaccinated } \\
\text { pregnant women } \\
\text { considered } \\
\text { any of the } \\
\text { following: } \\
\text { vaginal bleeding, } \\
\text { pregnancy loss, } \\
\text { hypertension, } \\
\text { gestational } \\
\text { diabetes, and } \\
\text { preterm birth }\end{array}$ \\
\hline
\end{tabular}

Bookstein

Peretz, 2021 [12] Israel, prospective, single-center
Pfizer-BioNTech BNT162b2 (2 doses)

Vaccine-induced immunity and adverse events associated with the BNT162b2 vaccine among pregnant women
mRNA vaccine during pregnancy seems not to increase the rate of pregnancy complications and is

effective in prevention of COVID-19 infection.

Favorable short-term obstetric and neonatal outcomes. The vaccine is effective in inducing humoral immunity in pregnant women, although SARS-CoV-2 IgG levels were lower when compared with those in nonpregnant vaccinated women. None of the pregnancies were complicated by fetal or neonatal death, and two $(3.5 \%)$ neonates required NICU admission for respiratory support.

\section{Vaccine} effectiveness of mRNA vaccines in preventing confirmed SARS-CoV-2 infection during pregnancy $>14$ days after the second dose of the vaccine
Vaccine effectiveness was 86.8\% (95\% CI: 47.5-98.5) $\geq 14$ days after the second dose. In the test-negative analysis, vaccine

effectiveness $>14$ days after the first dose but before the second dose was $40.8 \%(95 \%$ CI: 0.0-80.4). 
Table 1. Cont.

\begin{tabular}{|c|c|c|c|c|c|}
\hline $\begin{array}{l}\text { First Author, } \\
\text { Year }\end{array}$ & $\begin{array}{l}\text { Country, } \\
\text { Design }\end{array}$ & $\begin{array}{l}\text { Type of Vaccine } \\
\text { (Doses Given) }\end{array}$ & $\begin{array}{c}\text { Vaccinated } \\
\text { Pregnant } \\
\text { Women }(n)\end{array}$ & $\begin{array}{c}\text { First } \\
\text { Vaccine Dose } \\
\text { GA }^{*}\end{array}$ & Outcome \\
\hline $\begin{array}{c}\text { Cassaniti, } 2021 \\
{[14]}\end{array}$ & $\begin{array}{l}\text { Italy, } \\
\text { retrospective, } \\
\text { single-center }\end{array}$ & $\begin{array}{l}\text { Pfizer-BioNTech } \\
\text { BNT162b2 } \\
\text { (2 doses) }\end{array}$ & 2 & $31^{+4}$ and $27^{+6}$ & $\begin{array}{l}\text { Neutralizing } \\
\text { antibodies in } \\
\text { pregnant women } \\
\text { and newborns }\end{array}$ \\
\hline
\end{tabular}

Antibody transfer occurred efficiently from mothers showing anti-SARS-CoV-2 IgG at delivery (elicited either by infection or by vaccination). However, the median neutralizing titer was twofold reduced in newborns with respect to mothers. This may be due to the contributions to neutralization in maternal serum of spike-specific IgA levels, which are not transmitted to the fetus.

Binding, neutralizing, and functional non-neutralizing antibody responses, as well as CD4 and CD8 T-cell

Immunogenicity of the current COVID-19 mRNA

vaccines in pregnant and responses, were present in pregnant, lactating, and nonpregnant women following vaccination. Binding and neutralizing antibodies were also observed in infant cord blood and breast milk. Binding and neutralizing antibody titers against the SARS-CoV-2 B.1.1.7 and

B.1.351 variants of concern were reduced, but T-cell responses were preserved against viral variants.

High vaccine effectiveness of BNT162b2 was documented in pregnant women: estimated vaccine

Documented infection with SARS-CoV-2, symptomatic COVID-19, COVID-19related hospitalization, severe illness, and death effectiveness from 7 through

to 56 days after the second dose was $96 \%(95 \%$ CI: $89-100 \%$ ) for any

documented infection, $97 \%$ (91-100\%) for infections with documented symptoms and $89 \%$ (43-100\%) for COVID-19-related hospitalization. No deaths were observed.

Successful maternal to fetal transfer of neutralizing antibodies after vaccination with BNT162b2 in a pregnant woman at 25 weeks of gestation. The levels of neutralizing antibodies were capacity of umbilical cord blood compared to maternal blood approximately fivefold higher in the umbilical cord than in the maternal blood, while the level of total antibodies showed only a twofold increase.

Vaccination in pregnancy produced a robust immune response for the patient, with subsequent Antibodies in and in umbilical cord blood

\begin{tabular}{|c|c|c|c|c|c|c|}
\hline $\begin{array}{l}\text { and Jones, } \\
\text { 2021 } \\
\text { [17] }\end{array}$ & $\begin{array}{l}\text { United States, } \\
\text { case report }\end{array}$ & $\begin{array}{c}\text { Pfizer-BioNTech } \\
\text { BNT162b2 } \\
\text { (2 doses) }\end{array}$ & 1 & $32^{+6}$ & $\begin{array}{l}\text { maternal blood } \\
\text { and in umbilical } \\
\text { cord blood }\end{array}$ & $\begin{array}{l}\text { response for the patient, } \\
\text { with subsequent } \\
\text { transplacental transfer of } \\
\text { neutralizing antibodies }\end{array}$ \\
\hline
\end{tabular}


Table 1. Cont.

\begin{tabular}{|c|c|c|c|c|c|c|}
\hline $\begin{array}{l}\text { First Author, } \\
\text { Year }\end{array}$ & $\begin{array}{l}\text { Country, } \\
\text { Design }\end{array}$ & $\begin{array}{l}\text { Type of Vaccine } \\
\text { (Doses Given) }\end{array}$ & $\begin{array}{l}\text { Vaccinated } \\
\text { Pregnant } \\
\text { Women }(n)\end{array}$ & $\begin{array}{c}\text { First } \\
\text { Vaccine Dose } \\
\text { GA }^{*}\end{array}$ & Outcome & Conclusions \\
\hline $\begin{array}{c}\text { Gloeckner, } 2021 \\
{[18]}\end{array}$ & $\begin{array}{l}\text { Germany, } \\
\text { retrospective, } \\
\text { single-center }\end{array}$ & $\begin{array}{l}\text { Pfizer-BioNTech } \\
\text { BNT162b2 or } \\
\text { Moderna } \\
\text { mRNA-1273 after } \\
\text { a prime } \\
\text { vaccination with } \\
\text { Oxford- } \\
\text { AstraZeneca } \\
\text { ChAdOx1 (boost } \\
\text { vaccination with } \\
\text { a dose of mRNA } \\
\text { vaccine after a } \\
\text { prime vaccination } \\
\text { with a } \\
\text { vector-based } \\
\text { vaccine) }\end{array}$ & 3 & NA & $\begin{array}{c}\text { Antibody } \\
\text { kinetics following } \\
\text { heterologous } \\
\text { vaccination in } \\
\text { pregnant women } \\
\text { in comparison to } \\
\text { their newborns, } \\
\text { as well as to a } \\
\text { healthy } \\
\text { nonpregnant } \\
\text { control group }\end{array}$ & $\begin{array}{c}\text { Vaccine induced } \\
\text { SARS-CoV-2 spike IgG } \\
\text { antibodies after } \\
\text { vector-based prime } \\
\text { vaccination in pregnancy, } \\
\text { with an average increase of } \\
\text { more than one log10 level } \\
\text { after an mRNA-based boost. } \\
\text { No significant differences } \\
\text { were found compared with } \\
\text { nonpregnant controls. They } \\
\text { found similar levels of } \\
\text { anti-spike IgG antibodies } \\
\text { with a } \\
\text { high neutralization capacity } \\
\text { in the cord serum, } \\
\text { indicating a strong passive } \\
\text { humoral immunity in the } \\
\text { newborns. }\end{array}$ \\
\hline $\begin{array}{l}\text { Goldshtein, } \\
2021 \\
{[19]}\end{array}$ & $\begin{array}{l}\text { Israel, } \\
\text { retrospective, } \\
\text { multi-center }\end{array}$ & $\begin{array}{c}\text { Pfizer-BioNTech } \\
\text { BNT162b2 } \\
\text { (at least one dose) }\end{array}$ & 7530 & $\begin{array}{l}\text { 2nd and 3rd } \\
\text { trimester }\end{array}$ & $\begin{array}{l}\text { Documented } \\
\text { SARS-CoV-2 } \\
\text { infection } \\
28 \text { days or more } \\
\text { after the first } \\
\text { vaccine dose }\end{array}$ & $\begin{array}{c}\text { BNT162b2 mRNA } \\
\text { vaccination compared with } \\
\text { no vaccination was } \\
\text { associated with a } \\
\text { significantly lower risk of } \\
\text { SARS-CoV-2 infection. For } \\
28 \text { days or more } \\
\text { postvaccination, a } \\
\text { statistically significant } \\
\text { hazard reduction was } \\
\text { observed among the } \\
\text { vaccinated group compared } \\
\text { with the unvaccinated } \\
\text { group (aHR }=0.22 ; 95 \% C I: \\
0.11-0.43 ; \text { robust } p<0.001)\end{array}$ \\
\hline $\begin{array}{c}\text { Gray, } 2021 \\
{[40]}\end{array}$ & $\begin{array}{l}\text { United States, } \\
\text { retrospective, } \\
\text { multi-center }\end{array}$ & $\begin{array}{c}\text { Pfizer-BioNTech } \\
\text { BNT162b2 or } \\
\text { Moderna } \\
\text { mRNA-1273 } \\
\text { (2 doses) }\end{array}$ & 84 & $\begin{array}{c}23.2 \\
(I Q R ~ 16.3-32.1)\end{array}$ & $\begin{array}{l}\text { Vaccine-induced } \\
\text { immunity in } \\
\text { vaccinated } \\
\text { pregnant and } \\
\text { lactating women }\end{array}$ & $\begin{array}{l}\text { Robust and comparable IgG } \\
\text { titers } \\
\text { were observed across } \\
\text { pregnant, lactating, and } \\
\text { nonpregnant controls, all of } \\
\text { which were significantly } \\
\text { higher than those observed } \\
\text { in pregnant women with } \\
\text { previous SARS-CoV-2 } \\
\text { infection. Boosting } \\
\text { resulted in augmented IgG } \\
\text { levels in the blood, } \\
\text { translating to transfer of IgG } \\
\text { to the neonate through the } \\
\text { placenta and breast milk. }\end{array}$ \\
\hline $\begin{array}{c}\text { Kadali, } 2021 \\
\text { [20] }\end{array}$ & $\begin{array}{l}\text { United States, } \\
\text { prospective, } \\
\text { single-center }\end{array}$ & $\begin{array}{c}\text { Pfizer-BioNTech } \\
\text { BNT162b2 or } \\
\text { Moderna } \\
\text { mRNA-1273 } \\
\text { (at least one dose) }\end{array}$ & 38 & NA & $\begin{array}{l}\text { Side-effect profile } \\
\text { of the mRNA } \\
\text { vaccines among } \\
\text { pregnant } \\
\text { healthcare } \\
\text { workers (HCWs) } \\
\text { with that of } \\
\text { nonpregnant } \\
\text { HCWs }\end{array}$ & $\begin{array}{c}\text { No significant statistical } \\
\text { differences were found } \\
\text { between the groups for all } \\
\text { of the symptoms reported } \\
\text { for both groups (however, } \\
\text { the participant with a report } \\
\text { of seizure had a known } \\
\text { history of seizure disorder } \\
\text { and borderline low } \\
\text { anticonvulsant blood } \\
\text { levels). }\end{array}$ \\
\hline $\begin{array}{c}\text { Kashani- } \\
\text { Ligumsky, } 2021 \\
{[21]}\end{array}$ & $\begin{array}{c}\text { Israel, } \\
\text { prospective, } \\
\text { single-center }\end{array}$ & $\begin{array}{l}\text { Pfizer-BioNTech } \\
\text { BNT162b2 } \\
\text { (2 doses) }\end{array}$ & 29 & $\begin{array}{l}\text { 3rd } \\
\text { trimester }\end{array}$ & $\begin{array}{c}\text { Titers of IgG } \\
\text { antibodies to } \\
\text { SARS-CoV-2 in } \\
\text { umbilical cord } \\
\text { blood in } \\
\text { vaccinated } \\
\text { pregnant women }\end{array}$ & $\begin{array}{l}\text { Neonates born to mothers } \\
\text { vaccinated during } \\
\text { pregnancy had higher } \\
\text { antibody titers and may, } \\
\text { therefore, have more } \\
\text { prolonged protection } \\
\text { compared to those born to } \\
\text { women infected during } \\
\text { pregnancy. }\end{array}$ \\
\hline
\end{tabular}


Table 1. Cont.

\begin{tabular}{|c|c|c|c|c|c|c|}
\hline $\begin{array}{c}\text { First Author, } \\
\text { Year }\end{array}$ & $\begin{array}{l}\text { Country, } \\
\text { Design }\end{array}$ & $\begin{array}{l}\text { Type of Vaccine } \\
\text { (Doses Given) }\end{array}$ & $\begin{array}{l}\text { Vaccinated } \\
\text { Pregnant } \\
\text { Women }(n)\end{array}$ & $\begin{array}{c}\text { First } \\
\text { Vaccine Dose } \\
\text { GA }^{*}\end{array}$ & Outcome & Conclusions \\
\hline $\begin{array}{c}\text { Kharbanda, } \\
2021 \\
{[22]}\end{array}$ & $\begin{array}{l}\text { United States, } \\
\text { retrospective } \\
\text { case-control } \\
\text { surveillance } \\
\text { analysis of CDC } \\
\text { Vaccine Safety } \\
\text { Datalink }\end{array}$ & $\begin{array}{l}\text { Pfizer-BioNTech } \\
\text { BNT162b2 or } \\
\text { Moderna } \\
\text { mRNA-1273 or } \\
\text { Janssen vaccine } \\
\text { (at least one dose) }\end{array}$ & 21,267 & $6-19$ & $\begin{array}{c}\text { Case-control } \\
\text { surveillance of } \\
\text { COVID-19 } \\
\text { vaccination } \\
\text { during pregnancy } \\
\text { and spontaneous } \\
\text { abortion }\end{array}$ & $\begin{array}{c}\text { Spontaneous abortions did } \\
\text { not have an increased odds } \\
\text { of exposure to a COVID-19 } \\
\text { vaccination in the prior } 28 \\
\text { days compared with } \\
\text { ongoing pregnancies } \\
\text { (adjusted odds ratio, } 1.02 \text {; } \\
\text { 95\% CI: } 0.96-1.08 \text { ). Results } \\
\text { were consistent for } \\
\text { mRNA-1273 and BNT162b2 } \\
\text { and by gestational age } \\
\text { group. }\end{array}$ \\
\hline $\begin{array}{c}\text { Magnus, } 2021 \\
\text { [23] }\end{array}$ & $\begin{array}{l}\text { Norway, } \\
\text { case-control, } \\
\text { multi-center }\end{array}$ & $\begin{array}{c}\text { Pfizer-BioNTech } \\
\text { BNT162b2 or } \\
\text { Moderna } \\
\text { mRNA-1273 or } \\
\text { Oxford- } \\
\text { AstraZeneca } \\
\text { ChAdOx1 } \\
\text { (at least one dose) }\end{array}$ & 772 & NA & $\begin{array}{c}\text { Previous } \\
\text { COVID-19 } \\
\text { vaccination } \\
\text { and first-trimester } \\
\text { miscarriage risk } \\
\text { among women } \\
\text { who had a } \\
\text { miscarriage } \\
\text { before } 14 \text { weeks } \\
\text { of GA }\end{array}$ & $\begin{array}{l}\text { No evidence of an increased } \\
\text { risk for early pregnancy loss } \\
\text { after COVID-19 vaccination. }\end{array}$ \\
\hline $\begin{array}{c}\text { Mangat, } 2021 \\
{[24]}\end{array}$ & $\begin{array}{l}\text { United States, } \\
\text { case report }\end{array}$ & $\begin{array}{l}\text { Pfizer-BioNTech } \\
\text { BNT162b2 } \\
\text { (2 doses) }\end{array}$ & 1 & 22 & $\begin{array}{l}\text { Antibodies in } \\
\text { neonatal blood }\end{array}$ & $\begin{array}{c}\text { Persistence of } \\
\text { anti-SARS-CoV-2 S } \\
\text { antibodies was noted in a } \\
\text { preterm infant at } 6 \text { months } \\
\text { of age, which correlates with } \\
\text { the prevention of COVID-19 } \\
\text { and its complications in } \\
\text { early infancy. }\end{array}$ \\
\hline $\begin{array}{c}\text { Mehaffey, } 2021 \\
\text { [25] }\end{array}$ & $\begin{array}{l}\text { United States, } \\
\text { case report }\end{array}$ & $\begin{array}{l}\text { Pfizer-BioNTech } \\
\text { BNT162b2 } \\
\text { (2 doses) }\end{array}$ & 1 & 29 & $\begin{array}{l}\text { Antibodies in } \\
\text { maternal and } \\
\text { umbilical cord } \\
\text { blood }\end{array}$ & $\begin{array}{c}\text { Vertical transmission of IgG } \\
\text { SARS-CoV-2 specific } \\
\text { antibodies from a } \\
\text { vaccinated mother to her } \\
\text { son with no evidence of } \\
\text { prior infection. }\end{array}$ \\
\hline $\begin{array}{c}\text { Mithal, } 2021 \\
\text { [26] }\end{array}$ & $\begin{array}{l}\text { United States, } \\
\text { prospective, } \\
\text { single-center }\end{array}$ & $\begin{array}{c}\text { Pfizer-BioNTech } \\
\text { BNT162b2 or } \\
\text { Moderna } \\
\text { mRNA-1273 } \\
\text { (at least one dose) }\end{array}$ & 27 & $33 \pm 2$ & $\begin{array}{c}\text { Transfer of } \\
\text { SARS-CoV-2 IgG } \\
\text { to } \\
\text { infants following } \\
\text { maternal } \\
\text { vaccination } \\
\text { during } \\
\text { pregnancy }\end{array}$ & $\begin{array}{l}\text { Most pregnant women who } \\
\text { received a mRNA vaccine } \\
\text { during the third trimester } \\
\text { had transplacental transfer } \\
\text { of IgG to the infant. The } \\
\text { observed mean IgG transfer } \\
\text { ratio demonstrated that } \\
\text { infant antibody levels are } \\
\text { about equal to the maternal } \\
\text { levels. }\end{array}$ \\
\hline $\begin{array}{c}\text { Morgan, } 2021 \\
\text { [27] }\end{array}$ & $\begin{array}{l}\text { United Sates, } \\
\text { retrospective, } \\
\text { single-center }\end{array}$ & $\begin{array}{l}\text { Pfizer-BioNTech } \\
\text { BNT162b2 or } \\
\text { Moderna } \\
\text { mRNA-1273 or } \\
\text { Janssen vaccine } \\
\text { (at least one dose) }\end{array}$ & 1332 & NA & $\begin{array}{l}\text { Incidence of } \\
\text { severe or critical } \\
\text { COVID-19 in } \\
\text { vaccinated } \\
\text { compared with } \\
\text { unvaccinated } \\
\text { pregnant patients } \\
\text { in the context of } \\
\text { Delta variant } \\
\text { Predominance }\end{array}$ & $\begin{array}{l}\text { Association between } \\
\text { SARS-CoV-2 vaccination } \\
\text { and lower odds of severe or } \\
\text { critical COVID-19 and } \\
\text { COVID-19 of any severity in } \\
\text { pregnant patients during the } \\
\text { Delta variant-predominant } \\
\text { fourth surge of SARS-CoV-2. }\end{array}$ \\
\hline $\begin{array}{l}\text { Nir, } 2021 \\
\text { [28] }\end{array}$ & $\begin{array}{l}\text { Israel, } \\
\text { prospective, } \\
\text { single-center }\end{array}$ & $\begin{array}{l}\text { Pfizer-BioNTech } \\
\text { BNT162b2 } \\
\text { (2 doses) }\end{array}$ & 64 & $\begin{array}{c}\text { Mean } \pm \text { SD: } \\
33.5 \pm 3.2 \\
\text { weeks at } \\
\text { second dosage }\end{array}$ & $\begin{array}{l}\text { Antibodies in } \\
\text { maternal blood } \\
\text { and in umbilical } \\
\text { cord blood }\end{array}$ & $\begin{array}{c}\text { SARS-CoV-2 IgG antibodies } \\
\text { were detected in cord blood, } \\
\text { newborn dried blood spot, } \\
\text { and breast milk samples. } \\
\text { Neonatal and breast milk } \\
\text { antibody levels were } \\
\text { positively correlated with } \\
\text { maternal serum antibody } \\
\text { levels. Higher levels of cord } \\
\text { blood antibodies were } \\
\text { detected in vaccinated } \\
\text { women than in } \\
\text { COVID-19-recovered } \\
\text { women. }\end{array}$ \\
\hline
\end{tabular}


Table 1. Cont.

\begin{tabular}{|c|c|c|c|c|c|c|}
\hline $\begin{array}{l}\text { First Author, } \\
\text { Year }\end{array}$ & $\begin{array}{l}\text { Country, } \\
\text { Design }\end{array}$ & $\begin{array}{l}\text { Type of Vaccine } \\
\text { (Doses Given) }\end{array}$ & $\begin{array}{c}\text { Vaccinated } \\
\text { Pregnant } \\
\text { Women }(n)\end{array}$ & $\begin{array}{c}\text { First } \\
\text { Vaccine Dose } \\
\text { GA* }\end{array}$ & Outcome & Conclusions \\
\hline $\begin{array}{l}\text { Paul, } 2021 \\
\text { [29] }\end{array}$ & $\begin{array}{l}\text { United States, } \\
\text { case report }\end{array}$ & $\begin{array}{l}\text { Moderna } \\
\text { mRNA-1273 } \\
\text { (one dose) }\end{array}$ & (1) & 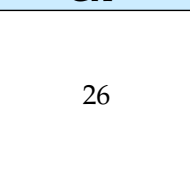 & $\begin{array}{l}\text { Antibodies in } \\
\text { umbilical cord } \\
\text { blood after } \\
\text { maternal } \\
\text { vaccination }\end{array}$ & $\begin{array}{l}\text { SARS-CoV-2 IgG antibodies } \\
\text { were detectable in a } \\
\text { newborn's cord blood } \\
\text { sample after only a single } \\
\text { dose of the Moderna } \\
\text { COVID-19 vaccine. }\end{array}$ \\
\hline $\begin{array}{c}\text { Prabhu, } 2021 \\
{[30]}\end{array}$ & $\begin{array}{l}\text { United States, } \\
\text { prospective, } \\
\text { single-center }\end{array}$ & $\begin{array}{l}\text { Pfizer-BioNTech } \\
\text { BNT162b2 or } \\
\text { Moderna } \\
\text { mRNA-1273 } \\
\text { (at least one dose) }\end{array}$ & 122 & NA & $\begin{array}{l}\text { Antibodies in } \\
\text { maternal blood } \\
\text { and in umbilical } \\
\text { cord blood }\end{array}$ & $\begin{array}{l}\text { All women and cord blood } \\
\text { samples, except for one, had } \\
\text { detectable IgG antibodies by } \\
4 \text { weeks after vaccine dose } 1 \text {. } \\
\text { The increasing levels of } \\
\text { maternal IgG over time and } \\
\text { the increasing placental IgG } \\
\text { transfer ratio over time } \\
\text { suggest that timing between } \\
\text { vaccination and birth may } \\
\text { be an important factor to } \\
\text { consider in vaccination } \\
\text { strategies of pregnant } \\
\text { women. }\end{array}$ \\
\hline
\end{tabular}

They demonstrated an efficient placental transfer of IgG antibodies following maternal SARS-CoV-2 vaccination, and a positive correlation between maternal and cord blood antibody concentrations.

Nevertheless, while neonatal antibody levels

Rottenstreich 2021

[31]
Israel, prospective, single-center
Pfizer-BioNTech BNT162b2 (at least one dose) $3^{\text {rd }}$ trimester
Antibodies in maternal blood and in umbilica cord blood were satisfactory, placental

transfer ratios were relatively lower $(0.44$ for anti-S and 0.34 for anti-RBD IgG) as compared to prior studies of vaccine-elicited antibodies to influenza, pertussis, measles, rubella, and hepatitis B, in which transfer ratios ranging from

0.8 to 1.7 have been reported.

The uptake of COVID-19 vaccination during the $3 \mathrm{rd}$ trimester of pregnancy was not associated with an increased risk of adverse maternal outcomes and lowered the risk for adverse neonatal outcomes

There was no observed increase in the incidence of findings characteristic of SARS-CoV-2 infection in pregnancy and no evidence of vaccine-triggered breakdown in maternal immunologic tolerance of the fetus. 
Table 1. Cont.

\begin{tabular}{|c|c|c|c|c|c|c|}
\hline $\begin{array}{l}\text { First Author, } \\
\text { Year }\end{array}$ & $\begin{array}{l}\text { Country, } \\
\text { Design }\end{array}$ & $\begin{array}{l}\text { Type of Vaccine } \\
\text { (Doses Given) }\end{array}$ & $\begin{array}{c}\text { Vaccinated } \\
\text { Pregnant } \\
\text { Women }(n)\end{array}$ & $\begin{array}{c}\text { First } \\
\text { Vaccine Dose } \\
\text { GA }^{*}\end{array}$ & Outcome & Conclusions \\
\hline $\begin{array}{c}\text { Shimabukuro, } \\
2021 \\
{[34]}\end{array}$ & $\begin{array}{c}\text { United States, } \\
\text { cross-sectional } \\
\text { survey }\end{array}$ & $\begin{array}{l}\text { Pfizer-BioNTech } \\
\text { BNT162b2 or } \\
\text { Moderna } \\
\text { mRNA-1273 (at } \\
\text { least one dose) }\end{array}$ & $\begin{array}{c}35,691 \\
\text { women }\end{array}$ & $\begin{array}{l}\text { Periconception } \\
\text { period }(2.3 \% \text {, } \\
\text { 1st trimester } \\
(28.6 \%), 2 \text { nd } \\
\text { trimester } \\
(43.3 \%), 3 \mathrm{rd} \\
\text { trimester } \\
(25.7 \%)\end{array}$ & $\begin{array}{l}\text { Participant- } \\
\text { reported local } \\
\text { and systemic } \\
\text { reactogenicity to } \\
\text { mRNA vaccines } \\
\text { and pregnancy } \\
\text { outcomes }\end{array}$ & $\begin{array}{l}\text { Injection-site pain was } \\
\text { reported more frequently } \\
\text { among pregnant persons } \\
\text { than among nonpregnant } \\
\text { women, whereas headache, } \\
\text { myalgia, chills, and fever } \\
\text { were reported less } \\
\text { frequently. Adverse } \\
\text { neonatal outcomes included } \\
\text { preterm birth (in } 9.4 \% \text { ) and } \\
\text { small size for gestational } \\
\text { age (in } 3.2 \%) \text {; no neonatal } \\
\text { deaths were reported. Most } \\
\text { abortions (92.3\%) occurred } \\
\text { before } 13 \text { weeks of gestation. }\end{array}$ \\
\hline $\begin{array}{c}\text { Trostle, } 2021 \\
\text { [35] }\end{array}$ & $\begin{array}{l}\text { United States, } \\
\text { prospective, } \\
\text { single-center }\end{array}$ & $\begin{array}{l}\text { Pfizer-BioNTech } \\
\text { BNT162b2 or } \\
\text { Moderna } \\
\text { mRNA-1273 (at } \\
\text { least one dose) }\end{array}$ & 36 & $\begin{array}{l}\text { 1st trimester } \\
(6 \%), 2 \mathrm{nd} \\
\text { trimester }(83 \%), \\
\text { 3rd trimester } \\
(11 \%)\end{array}$ & $\begin{array}{l}\text { Antibodies in } \\
\text { maternal blood } \\
\text { and in umbilical } \\
\text { cord blood }\end{array}$ & $\begin{array}{l}\text { Transplacental antibody } \\
\text { transfer following mRNA } \\
\text { COVID-19 vaccination } \\
\text { during pregnancy, with } \\
100 \% \text { of cord blood } \\
\text { specimens having high } \\
\text { levels of anti-S antibodies. }\end{array}$ \\
\hline $\begin{array}{c}\text { Wainstock, } 2021 \\
\text { [36] }\end{array}$ & $\begin{array}{l}\text { Israel, } \\
\text { retrospective, } \\
\text { single-center }\end{array}$ & $\begin{array}{c}\text { Pfizer-BioNTech } \\
\text { BNT162b2 (at } \\
\text { least one dose) }\end{array}$ & 913 & $\begin{array}{l}2 \text { nd or } 3 \mathrm{rd} \\
\text { trimester }\end{array}$ & $\begin{array}{c}\text { Associations } \\
\text { among prenatal } \\
\text { Pfizer-BioNTech } \\
\text { COVID-19 } \\
\text { vaccination, } \\
\text { pregnancy } \\
\text { Course, and } \\
\text { outcomes }\end{array}$ & $\begin{array}{l}\text { Prenatal maternal } \\
\text { COVID-19 vaccine had no } \\
\text { adverse effects on } \\
\text { pregnancy course and } \\
\text { outcomes. }\end{array}$ \\
\hline
\end{tabular}

The cumulative risk of spontaneous abortion from 6 to less than 20 weeks of gestation was $14.1 \%$ (95\% CI: 12.1-16.1) in the primary analysis and $12.8 \%(95 \% \mathrm{CI}$ :

10.8-14.8) in an analysis using direct maternal age standardization to the reference population. As

Pfizer-BioNTech BNT162b2 or Moderna mRNA-1273 United States, analysis of CDC

Zauche, 2021 [37] v-safe COVID-19 vaccine pregnancy registry

(at least one dose either before conception or

before 20 weeks of gestation)
2022 20 abortion from 6 to
less than 20
weeks of
gestation

Cumulative
risk of
spontaneous
abortion from 6 to
less than 20
weeks of
gestation

Cumulative compared with data from two historical cohorts that represent the lower and upper ranges of spontaneous abortion risk, the risk of spontaneous abortion after mRNA COVID-19 vaccination either before conception or during pregnancy was consistent with the expected risk of spontaneous abortion; these findings add to the accumulating evidence about the safety of mRNA COVID-19 vaccination in pregnancy.

High titers of anti-S antibodies in cord blood after birth, suggesting that maternal immunization may provide protection to newborns through the transplacental transfer of antibodies. The trend in the correlation coefficients of the number of weeks from the first vaccine dose to delivery is worth noting.
Antibodies in maternal blood nd in umbilica cord blood 
Comparing adverse effects in pregnant women and nonpregnant women, according Bookstein Peretz's data, there were no additional adverse effects of vaccination during pregnancy. Furthermore, the rate and the severity of adverse effects were unaffected by the timing of immunization during pregnancy [12].

Goldshtein et al. confirmed this trend, with only 68/7530 women vaccinated during pregnancy $(0.9 \%)$ reporting possible vaccine-related adverse events; none of them were serious. Headache $(0.1 \%)$, overall asthenia $(0.1 \%)$, unspecified pain $(<0.1 \%)$, and stomachache $(<0.1 \%)$ were the most often reported side-effects. Furthermore, mRNA immunization was linked to a considerably decreased probability of SARS-CoV-2 infection when compared to no immunization [19].

Two very large Israeli cohort studies provided data that support the safety of vaccination in pregnancy. The first is a retrospective study by Goldshtein et al. that looked at the relationship between immunization with Pfizer vaccine and the risk of infection in pregnant women who were vaccinated in the second and third trimesters of gestation. The primary outcome was SARS-CoV-2 infection demonstrated by the positivity of the molecular swab at 28 days after the initial vaccination dose. The cumulative incidence of infection in vaccinated women was significantly lower than in unvaccinated women. SARSCoV-2 hospitalization rates were $0.2 \%$ in the protected women and $0.3 \%$ in the unprotected peers. During the study's follow-up period, $18 \%$ of the vaccinated group and $18.9 \%$ of the unvaccinated group completed the pregnancy [19].

Dagan et al. in the second Israeli study compared a cohort of 10,861 pregnant women vaccinated with BNT162b2 mRNA matched 1:1 with 10,861 unvaccinated pregnant women. Twenty-six percent were immunized during the first trimester, $48 \%$ were immunized during the second trimester, and $26 \%$ were immunized during the third trimester. The results reflect the effectiveness of the vaccine against the alpha variant, which was predominantly circulating in Israel during the study period. The primary outcome was to determine the incidence of SARS-CoV-2 infection documented by a positive molecular swab and the incidence of symptoms and hospitalization. The periods in which the cumulative incidence was calculated were 14-20 days and 21-27 days following the first administration and 7-56 days following the second injection. The incidence of infection, as well as the risk of severe illness and hospitalization, was considerably greater in the unvaccinated group compared to the vaccinated group [15].

A very relevant question relates to the protective capacity of vaccination or natural infection for newborns. Several studies on this question have been performed. The most interesting was carried out in Boston on a cohort of 103 women protected with mRNA-1273 (Moderna) or BNT162b2 (Pfizer-BioNTech) vaccine, as well as 28 women with confirmed SARS-CoV-2 infection [39]: 30 vaccinated women were pregnant; 16 vaccinated women were post breastfeeding; 57 vaccinated women were neither pregnant nor breastfeeding. Among the 28 unvaccinated women, 22 were infected with SARS-CoV-2, while six were infected with SARS-CoV-2 and were breastfeeding. The authors measured the anti-SARS-CoV-2 receptor-binding domain (RBD) antibody titer and the neutralizing and non-neutralizing antibody titer after vaccination and after the natural infection. The presence of neutralizing and non-neutralizing antibodies and the response of $\mathrm{CD} 4^{+}$and $\mathrm{CD}^{+} \mathrm{T}$-cells were detectable in all subgroups and were also observed in the umbilical cord blood and human milk following immunization. The level of antibodies against variants B.1.1.7 and B.1.351 was decreased, but the cellular T response was conserved against these variants.

The presence of neutralizing antibodies in pregnant women and newborns following vaccination was confirmed in all cohorts. Interestingly, a surprising discovery is that the transfer ratio appears to rise with latency from immunization; these findings imply that earlier immunization, at least among women in their third trimester, may create a stronger protection in the baby, the immunobiology of which deserves additional study [26]. 


\subsection{Synthesis of Results in Lactating Women}

Questions are often asked about the presence of antibodies and mRNA in breast milk after COVID vaccine. The characteristics and most relevant findings of the included studies on vaccination during breastfeeding are reported in Table 2 . No major adverse reactions needing emergency treatment or hospitalization were described in mothers and infants.

Table 2. List of the 16 studies including pregnant mothers who received SARS-CoV-2 vaccination.

\begin{tabular}{|c|c|c|c|c|c|}
\hline $\begin{array}{c}\text { First } \\
\text { Author, Year }\end{array}$ & $\begin{array}{l}\text { Country, } \\
\text { Design }\end{array}$ & $\begin{array}{l}\text { Type of Vaccine } \\
\text { (Doses Given) }\end{array}$ & $\begin{array}{c}\text { Vaccinated } \\
\text { Lactating } \\
\text { Women }(n)\end{array}$ & Outcome & Conclusions \\
\hline $\begin{array}{l}\text { Baird, } 2021 \\
\quad[41]\end{array}$ & $\begin{array}{l}\text { United States, } \\
\text { prospective, } \\
\text { single-center }\end{array}$ & $\begin{array}{c}\text { Pfizer-BioNTech } \\
\text { BNT162b2 or } \\
\text { Moderna } \\
\text { mRNA-1273 } \\
\text { (2 doses) }\end{array}$ & 7 & $\begin{array}{l}\text { Antibodies in } \\
\text { human milk }\end{array}$ & $\begin{array}{l}\text { Significantly elevated levels of } \\
\text { SARS-CoV-2-specific IgG and IgA } \\
\text { antibodies in human milk } \\
\text { beginning approximately } 7 \text { days } \\
\text { after the initial vaccine dose, with } \\
\text { an IgG-dominant response. }\end{array}$ \\
\hline $\begin{array}{l}\text { Bertrand, } \\
2021 \\
{[42]}\end{array}$ & $\begin{array}{l}\text { United States, } \\
\text { prospective, } \\
\text { single-center }\end{array}$ & $\begin{array}{c}\text { Pfizer-BioNTech } \\
\text { BNT162b2 or } \\
\text { Moderna } \\
\text { mRNA-1273 } \\
\text { (2 doses) }\end{array}$ & 180 & $\begin{array}{c}\text { Safety of } \\
\text { vaccination in } \\
\text { breastfeeding } \\
\text { women and their } \\
\text { breastfed children }\end{array}$ & $\begin{array}{l}\text { More than } 85 \% \text { of } 180 \text { breastfeeding } \\
\text { women who received an mRNA } \\
\text { COVID-19 vaccine reported local or } \\
\text { systemic symptoms, with higher } \\
\text { frequency following the second } \\
\text { dose, but no serious adverse events } \\
\text { were noted. } \\
\text { Some women reported a temporary } \\
\text { reduction in milk supply, but the } \\
\text { milk supply returned to normal } \\
\text { within } 3 \text { days. Moreover, few } \\
\text { women reported an increase in milk } \\
\text { supply after each dose. }\end{array}$ \\
\hline
\end{tabular}

Serological profile of lactating women compared to nonlactating women, after

$\begin{array}{ccc}\text { Charepe, } & \text { Portugal, } & \text { Pfizer-BioNTech } \\ 2021 & \text { prospective, } & \text { BNT162b2 } \\ {[43]} & \text { single-center } & \text { (2 doses) }\end{array}$
14 immunization with the BNT162b2

Pfizer vaccine, in a cohort of healthcare workers, and antibody transfer via breast milk

mmunogenicity of the current

COVID-19 mRNA vaccines in pregnant and lactating women against both the original

SARS-CoV-2

USA-WA1/2020

strain and the

B.1.1.7 and B.1.351

variants of concern
All women showed immunity after vaccination with positive antibodies for $\operatorname{IgM}, \operatorname{IgA}$, and $\operatorname{IgG}$ antibodies.

The dominant serum antibody response was IgG. Modest levels of antibodies in the breast milk of lactating mothers were observed in this study, especially IgG in $42.9 \%$.

Binding, neutralizing, and functional non-neutralizing antibody responses, as well as CD4 and CD8 T-cell responses, were present in pregnant, lactating, and nonpregnant women following vaccination. Binding and neutralizing antibodies were also observed in infant cord blood and breast milk. Binding and neutralizing antibody titers against the SARS-CoV-2 B.1.1.7 and B.1.351 variants of concern were reduced, but T-cell responses were preserved against viral variants. 
Table 2. Cont.

\begin{tabular}{|c|c|c|c|c|c|}
\hline $\begin{array}{c}\text { First } \\
\text { Author, Year }\end{array}$ & $\begin{array}{l}\text { Country, } \\
\text { Design }\end{array}$ & $\begin{array}{l}\text { Type of Vaccine } \\
\text { (Doses Given) }\end{array}$ & $\begin{array}{l}\text { Vaccinated } \\
\text { Lactating } \\
\text { Women }(n)\end{array}$ & Outcome & Conclusions \\
\hline $\begin{array}{c}\text { Golan, } 2021 \\
\text { [44] }\end{array}$ & $\begin{array}{l}\text { United States, } \\
\text { prospective, } \\
\text { single-center }\end{array}$ & $\begin{array}{l}\text { Pfizer-BioNTech } \\
\text { BNT162b2 or } \\
\text { Moderna } \\
\text { mRNA-1273 } \\
\text { (at least one } \\
\text { dose) }\end{array}$ & 7 & $\begin{array}{l}\text { Detection of } \\
\text { vaccine-related } \\
\text { mRNA in human } \\
\text { milk after } \\
\text { vaccination }\end{array}$ & $\begin{array}{c}\text { Vaccine-associated mRNA was } \\
\text { not detected in } 13 \text { milk samples } \\
\text { collected } 4 \text { to } 48 \mathrm{~h} \text { after } \\
\text { vaccination from } 7 \\
\text { breastfeeding individuals. }\end{array}$ \\
\hline $\begin{array}{c}\text { Gray, } 2021 \\
{[40]}\end{array}$ & $\begin{array}{l}\text { United States, } \\
\text { prospective, } \\
\text { multi-center }\end{array}$ & $\begin{array}{l}\text { Pfizer-BioNTech } \\
\text { BNT162b2 or } \\
\text { Moderna } \\
\text { mRNA-1273 } \\
\text { (2 doses) }\end{array}$ & 31 & $\begin{array}{l}\text { Vaccine-induced } \\
\text { immunity in } \\
\text { vaccinated } \\
\text { pregnant and } \\
\text { lactating women }\end{array}$ & $\begin{array}{l}\text { Robust and comparable IgG } \\
\text { titers were observed across } \\
\text { pregnant, lactating, and } \\
\text { nonpregnant controls, all of } \\
\text { which } \\
\text { were significantly higher than } \\
\text { those observed in pregnant } \\
\text { women with previous } \\
\text { SARS-CoV-2 infection. Boosting } \\
\text { resulted in augmented IgG } \\
\text { levels in the blood, translating } \\
\text { to transfer of IgG to the neonate } \\
\text { through the placenta and breast } \\
\text { milk. }\end{array}$ \\
\hline
\end{tabular}

\begin{tabular}{|c|c|c|c|c|c|}
\hline $\begin{array}{c}\text { Guida, } 2021 \\
\text { [45] }\end{array}$ & $\begin{array}{c}\text { Italy, } \\
\text { prospective, } \\
\text { single-center }\end{array}$ & $\begin{array}{l}\text { Pfizer-BioNTech } \\
\text { BNT162b2 } \\
\text { (2 doses) }\end{array}$ & 10 & $\begin{array}{l}\text { Release of } \\
\text { SARS-CoV-2 Spike } \\
\text { (S) antibodies } \\
\text { in human milk } \\
\text { samples obtained } \\
\text { by patients } \\
\text { vaccinated with } \\
\text { the mRNA } \\
\text { BNT162b2 vaccine }\end{array}$ & $\begin{array}{l}\text { Seven days after the } 2 \text { nd dose, } \\
\text { anti-SARS-CoV- } 2 \mathrm{~S} \text { antibodies } \\
\text { were detected in all sera and in } \\
\text { all milk samples. The milk } \\
\text { antibodies/serum antibodies } \\
\text { ratio was on average } 2 \% \text {. }\end{array}$ \\
\hline $\begin{array}{l}\text { Jakuszko, } \\
2021 \\
{[46]}\end{array}$ & $\begin{array}{c}\text { Poland, } \\
\text { prospective, } \\
\text { single-center }\end{array}$ & $\begin{array}{l}\text { Pfizer-BioNTech } \\
\text { BNT162b2 } \\
\text { (2 doses) }\end{array}$ & 32 & $\begin{array}{l}\text { Immune response } \\
\text { to vaccination } \\
\text { against COVID-19 } \\
\text { in breastfeeding } \\
\text { women } \\
\text { and possible } \\
\text { benefits for both } \\
\text { mother and child }\end{array}$ & $\begin{array}{l}\text { As there were no serious } \\
\text { side-effects in the children after } \\
\text { the mothers' vaccinations, and } \\
\text { the presence of IgG and IgA } \\
\text { antibodies in the breast milk } \\
\text { was confirmed, the study gives } \\
\text { further evidence on the } \\
\text { importance of vaccination } \\
\text { against COVID-19 in } \\
\text { breastfeeding women. }\end{array}$ \\
\hline $\begin{array}{c}\text { Juncker, } 2021 \\
{[47]}\end{array}$ & $\begin{array}{c}\text { The Netherlands, } \\
\text { prospective, } \\
\text { single-center }\end{array}$ & $\begin{array}{c}\text { Pfizer-BioNTech } \\
\text { BNT162b2 } \\
\text { (at least one } \\
\text { dose) }\end{array}$ & 26 & $\begin{array}{l}\text { Levels of specific } \\
\text { IgA antibodies in } \\
\text { human milk } \\
\text { following the first } \\
\text { and second dose of } \\
\text { BNT162b2 }\end{array}$ & $\begin{array}{l}\text { In human milk, a biphasic } \\
\text { response was observed, with } \\
\text { SARS-CoV-2 specific IgA } \\
\text { starting to increase between } \\
\text { days } 5-7 \text { after the first dose and } \\
\text { declining after day 15, on } \\
\text { average. After the second dose, } \\
\text { an accelerated immune reaction } \\
\text { was observed. }\end{array}$ \\
\hline
\end{tabular}


Table 2. Cont.

\begin{tabular}{|c|c|c|c|c|c|}
\hline $\begin{array}{l}\text { First } \\
\text { Author, Year }\end{array}$ & $\begin{array}{l}\text { Country, } \\
\text { Design }\end{array}$ & $\begin{array}{l}\text { Type of Vaccine } \\
\text { (Doses Given) }\end{array}$ & $\begin{array}{l}\text { Vaccinated } \\
\text { Lactating } \\
\text { Women }(n)\end{array}$ & Outcome & Conclusions \\
\hline $\begin{array}{l}\text { Kelly, } 2021 \\
{[48]}\end{array}$ & $\begin{array}{l}\text { United States, } \\
\text { prospective, } \\
\text { single-center }\end{array}$ & $\begin{array}{l}\text { Pfizer-BioNTech } \\
\text { BNT162b2 } \\
\text { (2 doses) }\end{array}$ & 5 & $\begin{array}{l}\text { Antibodies in } \\
\text { human milk }\end{array}$ & $\begin{array}{c}\text { They characterized longitudinal } \\
\text { breast milk levels of anti-spike } \\
\text { IgG/A following BNT162b2 } \\
\text { vaccination, demonstrating } \\
\text { sustained elevation of IgG/IgA } \\
\text { levels. However, } \\
\text { individual-level data suggest a } \\
\text { possible gradual decline in } \\
\text { anti-spike IgA in human milk } \\
\text { over time after the second dose. }\end{array}$ \\
\hline $\begin{array}{c}\text { Lechosa- } \\
\text { Muñiz, } 2021 \\
\text { [49] }\end{array}$ & $\begin{array}{c}\text { Spain, } \\
\text { prospective, } \\
\text { single-center }\end{array}$ & $\begin{array}{l}\text { Pfizer-BioNTech } \\
\text { BNT162b2, } \\
\text { Moderna } \\
\text { mRNA-1273, or } \\
\text { Oxford- } \\
\text { AstraZeneca } \\
\text { ChAdOx1 } \\
\text { (2 doses of } \\
\text { mRNA vaccines } \\
\text { or just } 1 \text { dose of } \\
\text { vector-based } \\
\text { vaccine) }\end{array}$ & 110 & $\begin{array}{l}\text { Presence of IgG } \\
\text { and IgA antibodies } \\
\text { directed against } \\
\text { SARS-CoV-2 } \\
\text { protein S in blood } \\
\text { from breastfeeding } \\
\text { women and to } \\
\text { detect the presence } \\
\text { of IgA and IgG } \\
\text { isotype antibodies } \\
\text { directed against } \\
\text { SARS-CoV-2 } \\
\text { protein S in breast } \\
\text { milk }\end{array}$ & $\begin{array}{l}\text { The anti-SARS-CoV-2 vaccines } \\
\text { used were well tolerated by } \\
\text { mothers and breastfed infants. } \\
\text { Breastfeeding must not be } \\
\text { interrupted after vaccination. } \\
\text { They showed a positive } \\
\text { correlation between antibody } \\
\text { levels in serum and breast milk } \\
\text { samples (lower in who received } \\
\text { AstraZeneca). As an added } \\
\text { value, breastfeeding mothers } \\
\text { offer their infants IgA and IgG } \\
\text { isotype antibodies directed } \\
\text { against SARS-CoV-2 protein S } \\
\text { in breast milk. }\end{array}$ \\
\hline
\end{tabular}

Lactating mothers secreted specific $\operatorname{IgA}$ and $\operatorname{IgG}$ antibodies into milk, with the most significant increase at 3-7 days post dose 2. Virus-specific IgG titers were stable out to $4-6$ weeks after dose 2 . In contrast,

Low, 2021

[50]

$\begin{array}{cc}\text { Singapore, } & \text { Pfizer-BioNTech } \\ \text { prospective, } & \text { BNT162b2 } \\ \text { single-center } & \text { (2 doses) }\end{array}$

Production and secretion of spikeand receptor-binding domain

(RBD)-specific IgA and IgG into human milk
SARS-CoV-2-specific IgA levels showed substantial decay.

Infants who consumed post-vaccination human milk had no reported adverse effects up to 28 days post ingestion.

Minimal disruption of lactation or adverse impact on the breastfed child, more after the 2nd dose: $94 \%$ of women reported no changes in milk production or described an increase

Specific IgA and IgG antibodies were found in human milk for 6 weeks after vaccination. $\operatorname{Ig} \mathrm{A}$ secretion was evident as early as 2 weeks after vaccination followed by a spike in IgG after 4 weeks ( 1 week after the second vaccine). 
Table 2. Cont.

\begin{tabular}{|c|c|c|c|c|c|}
\hline $\begin{array}{c}\text { First } \\
\text { Author, Year }\end{array}$ & $\begin{array}{l}\text { Country, } \\
\text { Design }\end{array}$ & $\begin{array}{l}\text { Type of Vaccine } \\
\text { (Doses Given) }\end{array}$ & $\begin{array}{l}\text { Vaccinated } \\
\text { Lactating } \\
\text { Women }(n)\end{array}$ & Outcome & Conclusions \\
\hline $\begin{array}{l}\text { Piano } \\
\text { Mortari, } \\
2021 \\
{[53]}\end{array}$ & $\begin{array}{c}\text { Italy, } \\
\text { prospective, } \\
\text { single-center }\end{array}$ & $\begin{array}{l}\text { Pfizer-BioNTech } \\
\text { BNT162b2 } \\
\text { (2 doses) }\end{array}$ & 16 & $\begin{array}{l}\text { Measurement of } \\
\text { memory B cells } \\
\text { (MBCs) and } \\
\text { antibodies in } \\
\text { human milk }\end{array}$ & $\begin{array}{l}\text { Completing the vaccination } \\
\text { cycle is necessary to generate } \\
\text { high levels of specific serum } \\
\text { antibodies and MBCs. } \\
\text { Seven days after the second } \\
\text { vaccine dose, all lactating } \\
\text { mothers had detectable } \\
\text { spike-specific IgA in human } \\
\text { milk, confirming the ability of } \\
\text { vaccine-induced MBCs to be } \\
\text { home to the inflammatory } \\
\text { environment of the lactating } \\
\text { mammary gland and locally } \\
\text { produce IgA. }\end{array}$ \\
\hline $\begin{array}{c}\text { Romero } \\
\text { Ramírez, } \\
2021 \\
{[54]}\end{array}$ & $\begin{array}{c}\text { Spain, } \\
\text { prospective, } \\
\text { single-center }\end{array}$ & $\begin{array}{l}\text { Pfizer-BioNTech } \\
\text { BNT162b2 or } \\
\text { Moderna } \\
\text { mRNA-1273 } \\
\text { (2 doses) }\end{array}$ & 98 & $\begin{array}{l}\text { Antibodies in } \\
\text { human milk }\end{array}$ & $\begin{array}{l}\text { BNT162b2 and mRNA-1273 } \\
\text { COVID-19 vaccines generate } \\
\text { immunity in vaccinated } \\
\text { mothers and are associated with } \\
\text { vaccine-specific } \\
\text { immunoglobulin } \\
\text { concentrations in human milk. }\end{array}$ \\
\hline
\end{tabular}

It seems clear that, in the human milk of women protected with mRNA vaccines (currently preferentially indicated in Italy for women of reproductive age), there is a constant presence of anti-spike antibodies, particularly of the $\operatorname{IgA}$ and $\operatorname{IgG}$ type, as also shown by preliminary data from a study still in progress at the "Bambino Gesù" Children's Hospital in Rome [53].

The relationship between milk IgA antibodies and immunization timing during breastfeeding has to be researched further, considering the drop in IgA levels recently observed of up to $25 \%$ in a cohort of lactating women (probably deriving from the different timing of withdrawals) [55].

To date, the largest study is a cross-sectional survey performed by McLaurin-Jiang et al., who recruited 4455 vaccinated breastfeeding mothers. According to their findings, vaccination appears to have few negative effects on lactation despite the reported shortterm side-effects (such as fever, fatigue, or headache) [46], with resolution within $72 \mathrm{~h}$ after vaccination [51].

An increase in milk IgA levels is seen 2 weeks after the first dose of vaccine, and they are detectable in $86 \%$ of cases 2 weeks after the second dose; IgG was already detected just 1 week after the second dose $[40,48,52]$.

When compared to detectable levels following the first dose, maternal blood IgG levels rose sixfold following the second dose; a similar pattern of increase was observed for milk IgG levels, although whether this could stimulate adequate infant immunity or not still requires further studies [55].

No mRNA presence was detected, highlighting the fact that there is no transfer of mRNA to the baby via breast milk and no reason to discontinue breastfeeding for this reason at the time of vaccine administration [44].

To exclude that mRNA vaccine components could get into milk after immunization, polyethylene glycol was measured by Golan et al. in milk samples collected before and after vaccine administration, and its concentration did not significantly change [55]. 


\section{Discussion}

Primary prevention of infections in pregnancy through vaccination is one of the most successful public health programs of the last 10 years. It has led to a significant decrease in maternal and perinatal morbidity and deaths from influenza and whooping cough [56]. The frequency of COVID-19 vaccination is still relatively low among pregnant women worldwide. Shamshirsaz et al. demonstrated that vaccination acceptance was significantly associated with the history of influenza or pertussis vaccine administration during pregnancy (OR $=3.03 ; 95 \%$ CI: $1.37-6.73 ; p=0.006)$ [57].

Therefore COVID-19 infection in pregnancy has a course that is certainly more severe than in other periods of women's life. It can cause adverse effects on the course of pregnancy, such as preterm birth, even if the real possibility and frequency of maternal-fetal transmission are still under study.

According to Ciapponi et al., COVID-19 pregnant women had a twofold higher risk of requiring mechanical ventilation, whereas their neonates had a threefold higher risk of being hospitalized in the neonatal intensive care unit (NICU) [58]. Kazemi et al. noted a marked risk of abortion in infected mothers; one possible mechanism could be placental inflammation induced by viral particles [59]. Most infections in neonates and children arise from family clusters [60], linked to infected adult patients; they often exhibit only milder clinical signs [61]. Recently, a few case reports of neonates presenting with a multisystem inflammatory syndrome after maternal SARS-CoV-2 infection (MIS-N) were reported [62].

Lumbreras-Marquez et al. assessed that, if all pregnant women received immunization during the two months of May and June 2021, the total expected maternal deaths in Mexico would have firmly decreased [63].

Data from mRNA vaccine studies show that the vaccine safety, tolerability, and efficacy in immunization are similar in pregnant women and their nonpregnant peers [4]. Since mRNA vaccines appear to stimulate Toll-like receptor 3 and that such activation has been associated with negative gestational outcomes [5], Shanes et al. examined the placentas of 84 women who got a SARS-CoV-2 vaccine during pregnancy and 116 unvaccinated women. The authors found no raised incidence of deciduous arterial disease, fetal vascular dysfunction, chronic low-grade villitis, or chronic histiocytic intervillositis in the vaccinated group [33].

However, the speed with which these vaccines were developed and authorized caused some concerns in the communities, starting from the possible effects on fertility or child outcomes. Long-term statistics are obviously scarce and will remain so for some years. The COVID-19 Vaccines International Pregnancy Exposure Registry (C-VIPER) will systemically estimate the risk of obstetric outcomes, neonatal outcomes, and infant outcomes in pregnant women exposed to a COVID-19 vaccine from 30 days before to the first day of their last menstrual period to end of pregnancy compared to a matched unexposed group. To date, the estimated study completion date is 31 December 2025 [64].

Although pregnant women were excluded from the first trials, at the time of writing, there is absolutely no evidence or theoretical reason to believe that any of the COVID-19 vaccinations could impair future fertility to date [7].

Concerns have also been raised about the chance of spontaneous abortion (pregnancy loss that occurs at fewer than 20 weeks of gestational age), a frequent event that affects 11 to 22 percent of identified pregnancies. Analyzing the data of the CVC v-safe COVID-19 pregnancy registry, the cumulative risk was within the expected risk range when data were compared to two historical cohorts that represent the "normal" lower and upper ranges of spontaneous abortion risk [37].

This systematic review is limited by the statistical heterogeneity in results of previous studies (ranging from single case reports to multicenter studies) and the relatively small sample size of pregnant women available in the literature, considering that more than 9.5 billion shots of COVID-19 vaccines have already been administered globally, at the time of writing. 
However, we described the outcomes of a global cohort of 74,908 pregnant women and 5082 lactating women who received COVID-19 vaccination, and this can be considered an adequate sample to rule out any adverse effect in them and their infants.

Scientific societies agree in declaring these vaccines safe during pregnancy and breastfeeding.

The American College of Obstetricians and Gynecologists (ACOG) recommends that individuals over the age of 12, including pregnant and lactating women, receive a COVID19 vaccine or a series of vaccines [65]. The European Board and College of Obstetrics and Gynecology (EBCOG) also said that immunization should be offered to all pregnant women, after they have been adequately informed of the benefits, especially in pregnant women at high risk for the presence of comorbidities (obesity, diabetes, heart disease, lung disease). Furthermore, the EBCOG recommends immunization against COVID-19 for all breastfeeding women, in the absence of a particular contraindication [6].

Considering the still limited evidence of vaccine safety during the first trimester of pregnancy, the Italian National Institute of Health and the Italian Obstetric Surveillance System recently updated guidelines for COVID-19 vaccinations during pregnancy; they cautiously stated that pregnant women who desire to be vaccinated should consider benefits and risks, given that fever is one of the possible reactions to the vaccine [66], and that this can cause an increased risk of birth defects [67], more so than the vaccine itself.

\section{Conclusions}

In this review we summarize the current knowledge about maternal and neonatal outcomes after COVID-19 vaccination, in order to help clinicians be thoroughly informed and fight misinformation. Benefits of COVID-19 vaccination outweigh the risks during pregnancy for both mothers and infants. Indeed, available studies report a good maternal immune response, as well as the transfer of maternal antibodies to confer passive protection against SARS-CoV-2 in newborns following maternal vaccination. The existence of antiSARS-CoV-2 antibodies in breast milk suggests a possible specific protective effect on the newborn-infant after both maternal infection and vaccination, even if only clinical trials can provide scientific evidence.

It should be noted that the ability to protect oneself is not limited to the presence of circulating antibodies; next to these there are memory cells, which play a fundamental role in the response against SARS-CoV-2 in the event of virus exposure. Therefore, the potentiality of the cellular component (primarily lymphocytes) of breast milk to react to SARS-CoV-2 must be investigated.

Author Contributions: Conceptualization, D.U.D.R. and C.A.; methodology, D.U.D.R. and C.A.; software, D.U.D.R.; formal analysis, D.U.D.R. and C.A.; data curation, D.U.D.R. and C.A.; writingoriginal draft preparation, D.U.D.R.; writing-review and editing, G.S., A.D. and C.A.; supervision, G.S., A.D. and C.A. All authors read and agreed to the published version of the manuscript.

Funding: This research received no external funding.

Institutional Review Board Statement: Not applicable.

Informed Consent Statement: Not applicable.

Data Availability Statement: Not applicable.

Acknowledgments: The authors sincerely thank Roberto Salvatori (Johns Hopkins Hospital, Baltimore, US) for the linguistic revision of the manuscript.

Conflicts of Interest: The authors declare no conflict of interest.

\section{References}

1. Jamieson, D.J.; Rasmussen, S.A. An update on COVID-19 and pregnancy. Am. J. Obstet. Gynecol. 2021, 226, 177-186. [CrossRef]

2. Arthurs, A.L.; Jankovic-Karasoulos, T.; Roberts, C.T. COVID-19 in pregnancy: What we know from the first year of the pandemic. Biochim. Biophys. Acta (BBA)-Mol. Basis Dis. 2021, 1867, 166248. [CrossRef] 
3. Ellington, S.; Strid, P.; Tong, V.T.; Woodworth, K.; Galang, R.R.; Zambrano, L.D.; Nahabedian, J.; Anderson, K.; Gilboa, S.M. Characteristics of women of reproductive age with laboratory-confirmed SARS-CoV-2 infection by pregnancy status-United States, 22 January-7 June 2020. MMWR Morb. Mortal. Wkly Rep. 2020, 69, 769-775. [CrossRef] [PubMed]

4. Principi, N.; Esposito, S. Is the immunization of pregnant women against covid-19 justified? Vaccines 2021, 9, 970. [CrossRef] [PubMed]

5. Shook, L.L.; Fallah, P.N.; Silberman, J.N.; Edlow, A.G. COVID-19 Vaccination in Pregnancy and Lactation: Current Research and Gaps in Understanding. Front. Cell. Infect. Microbiol. 2021, 11, 899. [CrossRef]

6. Martins, I.; Louwen, F.; Ayres-de-Campos, D.; Mahmood, T. EBCOG position statement on COVID-19 vaccination for pregnant and breastfeeding women. Eur. J. Obstet. Gynecol. Reprod. Biol. 2021, 262, 256-258. [CrossRef]

7. Schaler, L.; Wingfield, M. COVID-19 vaccine-Can it affect fertility? Ir. J. Med. Sci. 2021, 1-3. [CrossRef] [PubMed]

8. Moher, D.; Liberati, A.; Tetzlaff, J.; Altman, D.G.; Altman, D.; PRISMA Group. Preferred reporting items for systematic reviews and meta-analyses: The PRISMA statement. PLoS Med. 2009, 6, e1000097. [CrossRef]

9. Beharier, O.; Plitman Mayo, R.; Raz, T.; Nahum Sacks, K.; Schreiber, L.; Suissa-Cohen, Y.; Chen, R.; Gomez-Tolub, R.; Hadar, E.; Gabbay-Benziv, R.; et al. Efficient maternal to neonatal transfer of antibodies against SARS-CoV-2 and BNT162b2 mRNA COVID-19 vaccine. J Clin. Investig. 2021, 131, e150319. [CrossRef]

10. Blakeway, H.; Prasad, S.; Kalafat, E.; Heath, P.T.; Ladhani, S.N.; le Doare, K.; Magee, L.A.; O’Brien, P.; Rezvani, A.; von Dadelszen, P.; et al. COVID-19 vaccination during pregnancy: Coverage and safety. Am. J. Obstet. Gynecol. 2021, 226, 236.e1-236.e14. [CrossRef]

11. Bleicher, I.; Kadour-Peero, E.; Sagi-Dain, L.; Sagi, S. Early exploration of COVID-19 vaccination safety and effectiveness during pregnancy: Interim descriptive data from a prospective observational study. Vaccine 2021, 39, 6535-6538. [CrossRef] [PubMed]

12. Bookstein Peretz, S.; Regev, N.; Novick, L.; Nachshol, M.; Goffer, E.; Ben-David, A.; Asraf, K.; Doolman, R.; Levin, E.G.; Regev Yochay, G.; et al. Short-term outcome of pregnant women vaccinated with BNT162b2 mRNA COVID-19 vaccine. Ultrasound Obstet. Gynecol. 2021, 58, 450-456. [CrossRef] [PubMed]

13. Butt, A.A.; Chemaitelly, H.; al Khal, A.; Coyle, P.V.; Saleh, H.; Kaleeckal, A.; Latif, A.N.; Bertollini, R.; Abou-Samra, A.B.; Abu-Raddad, L.J. SARS-CoV-2 vaccine effectiveness in preventing confirmed infection in pregnant women. J. Clin. Investig. 2021, 131, e153662. [CrossRef] [PubMed]

14. Cassaniti, I.; Percivalle, E.; Zelini, P.; Nanhorngue, K.N.; Parolo, A.; Bernardi, V.; Jorizzo, G.; Santer, P.; Perotti, F.; Spinillo, A.; et al. Both SARS-CoV-2 infection and vaccination in pregnancy elicited neutralizing antibodies in pregnant women and newborns. Clin. Microbiol. Infect. 2021, 27, 1708-1709. [CrossRef]

15. Dagan, N.; Barda, N.; Biron-Shental, T.; Makov-Assif, M.; Key, C.; Kohane, I.S.; Hernán, M.A.; Lipsitch, M.; Hernandez-Diaz, S.; Reis, B.Y.; et al. Effectiveness of the BNT162b2 mRNA COVID-19 vaccine in pregnancy. Nat. Med. 2021, 27, 1693-1695. [CrossRef]

16. Douxfils, J.; Gillot, C.; de Gottal, É.; Vandervinne, S.; Bayart, J.L.; Dogné, J.M.; Favresse, J. Efficient Maternal to Neonate Transfer of Neutralizing Antibodies after SARS-CoV-2 Vaccination with BNT162b2: A Case-Report and Discussion of the Literature. Vaccines 2021, 9, 907. [CrossRef]

17. Gill, L.; Jones, C.W. Severe Acute Respiratory Syndrome Coronavirus 2 (SARS-CoV-2) Antibodies in Neonatal Cord Blood After Vaccination in Pregnancy. Obstet. Gynecol. 2021, 137, 894-896. [CrossRef]

18. Gloeckner, S.; Hornung, F.; Heimann, Y.; Schleussner, E.; Deinhardt-Emmer, S.; Loeffler, B.; Zoellkau, J. Newborns' passive humoral SARS-CoV-2 immunity following heterologous vaccination of the mother during pregnancy. Am. J. Obstet. Gynecol. 2021, 226, 261-262. [CrossRef]

19. Goldshtein, I.; Nevo, D.; Steinberg, D.M.; Rotem, R.S.; Gorfine, M.; Chodick, G.; Segal, Y. Association Between BNT162b2 Vaccination and Incidence of SARS-CoV-2 Infection in Pregnant Women. JAMA 2021, 326, 728-735. [CrossRef]

20. Kadali, R.A.K.; Janagama, R.; Peruru, S.R.; Racherla, S.; Tirumala, R.; Madathala, R.R.; Gajula, V. Adverse effects of COVID-19 messenger RNA vaccines among pregnant women: A cross-sectional study on healthcare workers with detailed self-reported symptoms. Am. J. Obstet. Gynecol. 2021, 225, 458-460. [CrossRef]

21. Kashani-Ligumsky, L.; Lopian, M.; Cohen, R.; Senderovich, H.; Czeiger, S.; Halperin, A.; Chaim, A.B.; Kremer, I.; Lessing, J.B.; Somekh, E.; et al. Titers of SARS-CoV-2 antibodies in cord blood of neonates whose mothers contracted SARS CoV-2 (COVID-19) during pregnancy and in those whose mothers were vaccinated with mRNA to SARS CoV-2 during pregnancy. J. Perinatol. 2021, 41, 2621-2624. [CrossRef] [PubMed]

22. Kharbanda, E.O.; Haapala, J.; DeSilva, M.; Vazquez-Benitez, G.; Vesco, K.K.; Naleway, A.L.; Lipkind, H.S. Spontaneous Abortion Following COVID-19 Vaccination During Pregnancy. JAMA 2021, 326, 1629-1631. [CrossRef] [PubMed]

23. Magnus, M.C.; Gjessing, H.K.; Eide, H.N.; Wilcox, A.J.; Fell, D.B.; Håberg, S.E. Covid-19 Vaccination during Pregnancy and First-Trimester Miscarriage. N. Engl. J. Med. 2021, 385, 2008-2010. [CrossRef] [PubMed]

24. Mangat, C.; Milosavljevic, N. BNT162b2 Vaccination during Pregnancy Protects Both the Mother and Infant: Anti-SARS-CoV-2 S Antibodies Persistently Positive in an Infant at 6 Months of Age. Case Rep. Pediatr. 2021, 2021, 6901131. [CrossRef]

25. Mehaffey, J.H.; Arnold, M.; Huffstetler, E.; Mehaffey, R.L.; Quillian, H.; Mehaffey, J.H. Successful vertical transmission of SARS-CoV-2 antibodies after maternal vaccination. Birth 2021, 48, 451-452. [CrossRef]

26. Mithal, L.B.; Otero, S.; Shanes, E.D.; Goldstein, J.A.; Miller, E.S. Cord blood antibodies following maternal coronavirus disease 2019 vaccination during pregnancy. Am. J. Obstet. Gynecol. 2021, 225, 192-194. [CrossRef] 
27. Morgan, J.A.; Biggio, J.R.; Martin, J.K.; Mussarat, N.; Chawla, H.K.; Puri, P.; Williams, F.B. Maternal Outcomes After Severe Acute Respiratory Syndrome Coronavirus 2 (SARS-CoV-2) Infection in Vaccinated Compared With Unvaccinated Pregnant Patients. Obstet. Gynecol. 2022, 139, 107-109. [CrossRef]

28. Nir, O.; Schwartz, A.; Toussia-Cohen, S.; Leibovitch, L.; Strauss, T.; Asraf, K.; Doolman, R.; Sharabi, S.; Cohen, C.; Lustig, Y.; et al. Maternal-neonatal transfer of SARS-CoV-2 immunoglobulin G antibodies among parturient women treated with BNT162b2 messenger RNA vaccine during pregnancy. Am. J. Obstet. Gynecol. MFM 2021, 4, 100492. [CrossRef]

29. Paul, G.; Chad, R. Newborn antibodies to SARS-CoV-2 detected in cord blood after maternal vaccination-A case report. BMC Pediatr. 2021, 21, 138. [CrossRef]

30. Prabhu, M.; Murphy, E.A.; Sukhu, A.C.; Yee, J.; Singh, S.; Eng, D.; Zhao, Z.; Riley, L.E.; Yang, Y.J. Antibody Response to Coronavirus Disease 2019 (COVID-19) Messenger RNA Vaccination in Pregnant Women and Transplacental Passage Into Cord Blood. Obstet. Gynecol. 2021, 138, 278-280. [CrossRef]

31. Rottenstreich, A.; Zarbiv, G.; Oiknine-Djian, E.; Zigron, R.; Wolf, D.G.; Porat, S. Efficient maternofetal transplacental transfer of anti-SARS-CoV-2 spike antibodies after antenatal SARS-CoV-2 BNT162b2 mRNA vaccination. Clin. Infect. Dis. 2021, 73, 1909-1912. [CrossRef] [PubMed]

32. Rottenstreich, M.; Sela, H.Y.; Rotem, R.; Kadish, E.; Wiener-Well, Y.; Grisaru-Granovsky, S. Covid-19 vaccination during the third trimester of pregnancy: Rate of vaccination and maternal and neonatal outcomes, a multicentre retrospective cohort study. BJOG 2022, 129, 248-255. [CrossRef] [PubMed]

33. Shanes, E.D.; Otero, S.; Mithal, L.B.; Mupanomunda, C.A.; Miller, E.S.; Goldstein, J.A. Severe Acute Respiratory Syndrome Coronavirus 2 (SARS-CoV-2) Vaccination in Pregnancy: Measures of Immunity and Placental Histopathology. Obstet. Gynecol. 2021, 138, 281-283. [CrossRef] [PubMed]

34. Shimabukuro, T.T.; Kim, S.Y.; Myers, T.R.; Moro, P.L.; Oduyebo, T.; Panagiotakopoulos, L.; Marquez, P.L.; Olson, C.K.; Liu, R.; Chang, K.T.; et al. Preliminary Findings of mRNA Covid-19 Vaccine Safety in Pregnant Persons. N. Engl. J. Med. 2021, 384, 2273-2282. [CrossRef]

35. Trostle, M.E.; Aguero-Rosenfeld, M.E.; Roman, A.S.; Lighter, J.L. High antibody levels in cord blood from pregnant women vaccinated against COVID-19. Am. J. Obstet. Gynecol. MFM 2021, 3, 100481. [CrossRef]

36. Wainstock, T.; Yoles, I.; Sergienko, R.; Sheiner, E. Prenatal maternal COVID-19 vaccination and pregnancy outcomes. Vaccine 2021, 39, 6037-6040. [CrossRef]

37. Zauche, L.H.; Wallace, B.; Smoots, A.N.; Olson, C.K.; Oduyebo, T.; Kim, S.Y.; Petersen, E.E.; Ju, J.; Beauregard, J.; Wilcox, A.J.; et al Receipt of mRNA Covid-19 Vaccines and Risk of Spontaneous Abortion. N. Engl. J. Med. 2021, 385, 1533-1535. [CrossRef]

38. Zdanowski, W.; Waśniewski, T. Evaluation of SARS-CoV-2 Spike Protein Antibody Titers in cord blood after COVID-19 vaccination during pregnancy in Polish healthcare workers: Preliminary results. Vaccines 2021, 9, 675. [CrossRef]

39. Collier, A.R.Y.; McMahan, K.; Yu, J.; Tostanoski, L.H.; Aguayo, R.; Ansel, J.; Chandrashekar, A.; Patel, S.; Apraku Bondzie, E.; Sellers, D.; et al. Immunogenicity of COVID-19 mRNA Vaccines in Pregnant and Lactating Women. JAMA 2021, 325, 2370-2380. [CrossRef]

40. Gray, K.J.; Bordt, E.A.; Atyeo, C.; Deriso, E.; Akinwunmi, B.; Young, N.; Baez, A.M.; Shook, L.L.; Cvrk, D.; James, K.; et al Coronavirus disease 2019 vaccine response in pregnant and lactating women: A cohort study. Am. J. Obstet. Gynecol. 2021, 225, 303.e1-303.e17. [CrossRef]

41. Baird, J.K.; Jensen, S.M.; Urba, W.J.; Fox, B.A.; Baird, J.R. SARS-CoV-2 Antibodies Detected in Mother's Milk Post-Vaccination. J. Hum. Lact. 2021, 37, 492-498. [CrossRef] [PubMed]

42. Bertrand, K.; Honerkamp-Smith, G.; Chambers, C.D. Maternal and Child Outcomes Reported by Breastfeeding Women following Messenger RNA COVID-19 Vaccination. Breastfeed. Med. 2021, 16, 697-701. [CrossRef] [PubMed]

43. Charepe, N.; Gonçalves, J.; Juliano, A.M.; Lopes, D.G.; Canhão, H.; Soares, H.; Serrano, E.F. COVID-19 mRNA vaccine and antibody response in lactating women: A prospective cohort study. BMC Pregnancy Childbirth 2021, 21, 632. [CrossRef] [PubMed]

44. Golan, Y.; Prahl, M.; Cassidy, A.; Lin, C.Y.; Ahituv, N.; Flaherman, V.J.; Gaw, S.L. Evaluation of Messenger RNA From COVID-19 BTN162b2 and mRNA-1273 Vaccines in Human Milk. JAMA Pediatr 2021, 175, 1069-1071. [CrossRef]

45. Guida, M.; Terracciano, D.; Cennamo, M.; Aiello, F.; la Civita, E.; Esposito, G.; Gargiulo, V.; Maruotti, G.M.; Portella, G.; Sarno, L. COVID-19 Vaccine mRNABNT162b2 Elicits Human Antibody Response in Milk of Breastfeeding Women. Vaccines 2021, 9, 785. [CrossRef]

46. Jakuszko, K.; Kościelska-Kasprzak, K.; Żabińska, M.; Bartoszek, D.; Poznański, P.; Rukasz, D.; Rukasz, D.; Kłak, R.; Królak-Olejnik, B.; Krajewska, M. Immune response to vaccination against covid-19 in breastfeeding health workers. Vaccines 2021, 9, 663. [CrossRef]

47. Juncker, H.G.; Mulleners, S.J.; van Gils, M.J.; de Groot, C.J.M.; Pajkrt, D.; Korosi, A.; van Goudoever, J.B.; van Keulen, B.J. The Levels of SARS-CoV-2 Specific Antibodies in Human Milk Following Vaccination. J. Hum. Lact. 2021, 37, 477-484. [CrossRef]

48. Kelly, J.C.; Carter, E.B.; Raghuraman, N.; Nolan, L.S.; Gong, Q.; Lewis, A.N.; Good, M. Anti-severe acute respiratory syndrome coronavirus 2 antibodies induced in breast milk after Pfizer-BioNTech/BNT162b2 vaccination. Am. J. Obstet. Gynecol. 2021, 225, 101-103. [CrossRef] 
49. Lechosa-Muñiz, C.; Paz-Zulueta, M.; Mendez-Legaza, J.M.; Irure-Ventura, J.; Cuesta González, R.; Calvo Montes, J.; López-Hoyos, M.; Llorca, J.; Cabero-Pérez, M.J. Induction of SARS-CoV-2-Specific IgG and IgA in Serum and Milk with Different SARS-CoV-2 Vaccines in Breastfeeding Women: A Cross-Sectional Study in Northern Spain. Int. J. Environ. Res. Public Health 2021, $18,8831$. [CrossRef]

50. Low, J.M.; Gu, Y.; Ng, M.S.F.; Amin, Z.; Lee, L.Y.; Ng, Y.P.M.; Shunmuganathan, B.D.; Niu, Y.; Gupta, R.; Tambyah, P.A.; et al. Codominant IgG and IgA expression with minimal vaccine mRNA in milk of BNT162b2 vaccinees. NPJ Vaccines 2021, 6, 105. [CrossRef]

51. McLaurin-Jiang, S.; Garner, C.D.; Krutsch, K.; Hale, T.W. Maternal and Child Symptoms following COVID-19 Vaccination among Breastfeeding Mothers. Breastfeed. Med. 2021, 16, 702-709. [CrossRef]

52. Perl, S.H.; Uzan-Yulzari, A.; Klainer, H.; Asiskovich, L.; Youngster, M.; Rinott, E.; Youngster, I. SARS-CoV-2-Specific Antibodies in Breast Milk After COVID-19 Vaccination of Breastfeeding Women. JAMA 2021, 325, 2013-2014. [CrossRef] [PubMed]

53. Piano Mortari, E.; Russo, C.; Vinci, M.R.; Terreri, S.; Fernandez Salinas, A.; Piccioni, L.; Alteri, C.; Colagrossi, L.; Coltella, L.; Ranno, S.; et al. Highly Specific Memory B Cells Generation after the 2nd Dose of BNT162b2 Vaccine Compensate for the Decline of Serum Antibodies and Absence of Mucosal IgA. Cells 2021, 10, 2541. [CrossRef] [PubMed]

54. Romero Ramirez, D.S.; Lara Pérez, M.M.; Carretero Pérez, M.; Suarez Hernandez, M.I.; Martin Pulido, S.; Pera Villacampa, L.; Fernández Vilar, A.M.; Rivero Falero, M.; González Carretero, P.; Reyes Millán, B.; et al. SARS-CoV-2 Antibodies in Breast Milk After Vaccination. Pediatrics 2021, 148, e2021052286. [CrossRef] [PubMed]

55. Golan, Y.; Prahl, M.; Cassidy, A.G.; Gay, C.; Wu, A.H.B.; Jigmeddagva, U.; Lin, C.Y.; Gonzalez, V.J.; Basilio, E.; Chidboy, M.A.; et al. COVID-19 mRNA Vaccination in Lactation: Assessment of Adverse Events and Vaccine Related Antibodies in Mother-Infant Dyads. Front. Immunol. 2021, 12, 777103. [CrossRef] [PubMed]

56. Mackin, D.W.; Walker, S.P. The historical aspects of vaccination in pregnancy. Best Pract. Res. Clin. Obstet. Gynaecol. 2021, 76, 13-22. [CrossRef] [PubMed]

57. Shamshirsaz, A.A.; Hessami, K.; Morain, S.; Afshar, Y.; Nassr, A.A.; Arian, S.E.; Asl, N.M.; Aagaard, K. Intention to Receive COVID-19 Vaccine during Pregnancy: A Systematic Review and Meta-analysis. Am. J. Perinatol. 2021. [CrossRef]

58. Ciapponi, A.; Bardach, A.; Comandé, D.; Berrueta, M.; Argento, F.J.; Rodriguez Cairoli, F.; Zamora, N.; Santa María, V.; Xiong, X.; Zaraa, S.; et al. COVID-19 and pregnancy: An umbrella review of clinical presentation, vertical transmission, and maternal and perinatal outcomes. PLoS ONE 2021, 16, e0253974. [CrossRef]

59. Kazemi, S.N.; Hajikhani, B.; Didar, H.; Hosseini, S.S.; Haddadi, S.; Khalili, F.; Mirsaeidi, M.; Nasiri, M.J. COVID-19 and cause of pregnancy loss during the pandemic: A systematic review. PLoS ONE 2021, 16, e0255994. [CrossRef]

60. Olivini, N.; Calò Carducci, F.I.; Santilli, V.; de Ioris, M.A.; Scarselli, A.; Alario, D.; Geremia, C.; Lombardi, M.H.; Marabotto, C.; Mariani, R.; et al. A neonatal cluster of novel coronavirus disease 2019: Clinical management and considerations. Ital. J. Pediatr. 2020, 46, 180. [CrossRef]

61. Garazzino, S.; Montagnani, C.; Donà, D.; Meini, A.; Felici, E.; Vergine, G.; Bernardi, S.; Giacchero, R.; Lo Vecchio, A.; Marchisio, P.; et al. Multicentre Italian study of SARS-CoV-2 infection in children and adolescents, preliminary data as at 10 April 2020. Eurosurveillance 2020, 25, 2000600. [CrossRef] [PubMed]

62. Lakshminrusimha, S.; Hudak, M.; Dimitriades, V.; Higgins, R. Multisystem Inflammatory Syndrome (MIS-C) in Neonates (MIS-N) Following Maternal SARS CoV-2 COVID-19 Infection. Am. J. Perinatol. 2021. [CrossRef]

63. Lumbreras-Marquez, M.I.; Fields, K.G.; Campos-Zamora, M.; Rodriguez-Bosch, M.R.; Rodriguez-Sibaja, M.J.; Copado-Mendoza, D.Y.; Acevedo-Gallegos, S.; Farber, M.K. A forecast of maternal deaths with and without vaccination of pregnant women against COVID-19 in Mexico. Int. J. Gynaecol. Obstet. 2021, 154, 566-567. [CrossRef]

64. COVID-19 Vaccines International Pregnancy Exposure Registry (C-VIPER)—ClinicalTrials.gov—Identifier: NCT04705116. 2021. Available online: https:/ / clinicaltrials.gov/ct2/show/study/NCT04705116 (accessed on 22 November 2021).

65. The American College of Obstetricians and Gynecologists (ACOG). COVID-19 Vaccination Considerations for ObstetricGynecologic Care. 2021. Available online: https://www.acog.org/clinical/clinical-guidance/practice-advisory/articles/2020/1 2/covid-19-vaccination-considerations-for-obstetric-gynecologic-care (accessed on 22 November 2021).

66. Italian National Institute of Health and Italian Obstetric Surveillance System, Rome (Italy). Ad Interim Indications on "COVID-19 Vaccination during Pregnancy and Breastfeeding" (Update of 2021, September 22). Available online: https:/ / www.epicentro.iss. it/en/vaccines/covid-19-pregnancy-breastfeeding (accessed on 22 November 2021).

67. Graham, J.M., Jr. Update on the gestational effects of maternal hyperthermia. Birth Defects Res. 2020, 112, 943-952. [CrossRef] [PubMed] 